\title{
A Statistical Evalution of Some Columbia River Basalt Chemical Analyses
}

F. Asaro

H. V. Michel

C. W. Myers

May 1978

Prepared for the United States

Department of Energy

Under Contract EY-77-C-06-1030

Rockwell International

Atomics International Division Rockwell Hanford Operations Richland, WA 99352 


\section{DISCLAIMER}

This report was prepared as an account of work sponsored by an agency of the United States Government. Neither the United States Government nor any agency Thereof, nor any of their employees, makes any warranty, express or implied, or assumes any legal liability or responsibility for the accuracy, completeness, or usefulness of any information, apparatus, product, or process disclosed, or represents that its use would not infringe privately owned rights. Reference herein to any specific commercial product, process, or service by trade name, trademark, manufacturer, or otherwise does not necessarily constitute or imply its endorsement, recommendation, or favoring by the United States Government or any agency thereof. The views and opinions of authors expressed herein do not necessarily state or reflect those of the United States Government or any agency thereof. 


\section{DISCLAIMER}

Portions of this document may be illegible in electronic image products. Images are produced from the best available original document. 


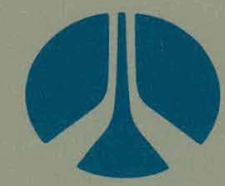

\section{Rockwell International}

Atomics International Division

Rockwell Hanford Operations

Richland, WA 99352

\section{NOTICE}

This Report was prepared as an account of work sponsored by the United States Government. Neither the United States nor the United States Department of Energy, nor any of their Employees, nor any of their Contractors, Subcontractors, or their Employees, makes any warranty, express or implied, or assumes any legal liability or responsibility for the accuracy, completeness, or usefulness of any information, apparatus, product or process disclosed, or represents that its use would not infringe privately owned rights.

AVAILABLE FROM THE

NATIONAL TECHNICAL INFORMATION SERVICE

SPRINGFIELD, VA. 22161

PRICE: MICROFICHE: $\$ 3.00$

PAPER COPY: $\$ 5.25$ 
Distr. Category UC-11

Distr. Category UC-70

A STATISTICAL EVALUATION OF SOME

COLUMBIA RIVER BASALT CHEMICAL ANALYSES

F. Asaro

H. V. Michel

Lawrence Berkeley Laboratory

and

C. W. Myers

Rockwell. Hanford Operations

$$
\begin{aligned}
& \text { This report was prepared as an account of work } \\
& \text { sponsored by the United States Government. Neither the } \\
& \text { United States nor the United States Department of } \\
& \text { Energy, nor any of their employees, nor any of their } \\
& \text { contractors, subcontractors, or their employees, makes } \\
& \text { any warranty, express or implied, or assumes any legal } \\
& \text { liability or responsibility for the accuracy, completeness } \\
& \text { or use fulness of any information, apparatus, product or } \\
& \text { process disclosed, or represents that its use would not } \\
& \text { infringe privately owned rights. }
\end{aligned}
$$

May 1978

Rockwell International

Atomics International Division

Rockwell Hanford operations

Richland, Washington 99352 
TABLE OF CONTENTS

\begin{tabular}{|c|c|}
\hline & Page \\
\hline ABSTRACT & 4 \\
\hline CONCLUSIONS & 5 \\
\hline OVERALL QUALITY OF THE CHEMICAL DATA & .5 \\
\hline CHEMICAL CHARACTERIZATIONS OF INDIVIDUAL BASALT UNITS & 6 \\
\hline CHEMICAL CORRELATIONS OF INDIVIDUAL BASALT UNITS & 6 \\
\hline STRATIGRAPHIC LIMITATIONS OF RESULTS & 7 \\
\hline INTRODUCTION & 8 \\
\hline PURPOSE & 8 \\
\hline GENERAL GEOLOGY & 8 \\
\hline BASALT STRATIGRAPHY & 9 \\
\hline SOURCE OF DATA & 12 \\
\hline EVALUATION OF CHEMICAL DATA & 13 \\
\hline ANALYTICAL TECHNIQUES AND STATISTICAL PROCEDURES & 13 \\
\hline RESULTS & 16 \\
\hline TYPE LOCALITY CHARACTERIZATION & 19 \\
\hline STATISTICAL PROCEDURES & 19 \\
\hline RESULTS & 28 \\
\hline $\begin{array}{l}\text { CORRELATIONS BETWEEN BOREHOLE SAMPLES AND REFERENCE } \\
\text { SAMPLES. }\end{array}$ & 31 \\
\hline STATISTICAL PROCEDURE & 31 \\
\hline RFEUTTSS & 32 \\
\hline DDH-1 COMPARISONS & 33 \\
\hline DH-2 COMPARISONS & 35 \\
\hline DDH- 3 COMPARISONS & 36 \\
\hline DH-4 COMPARISONS & 40 \\
\hline DH-5 COMPARISONS & 44 \\
\hline
\end{tabular}


TABLE OF CONTENTS (continued)'

APPENDIX A

Page

ACKNOWLEDGMENTS

57

REFERENCES

58

DISTRIBUTION

LIST OF FIGURES

FIGURE 1
FIGURE 2
FIGURE 3
FIGURE A-1
THROUGH
FIGURE A-10

INDEX MAP

10

STRATIGRAPHY OF THE PASCO BASIN

11

TYPE LOCALITY SAMPLE VERSUS TYPE

LOCALITY GROUP COMPARISONS

29

CORE HOLE CORRELA'IIONS WITH TYPE

47

LOCALITY GROUPS

\section{LIST OF TABLES}

TABLE I

SUMMARY OF EVALUATION OF ROCKWELL HANFORD OPERATIONS' CHEMICAL DATA

TABLE II

USEFULNESS OF VARIOUS ELEMENTS AS MEASURED BY ROCKWELL HANFORD OPERATIONS FOR CHARACTERIZATION

TABLE III

TYPE LOCALITY GROUP

TABLE IV

ROCKWELL HANFORD OPERATIONS' BASALT SAMPLES COMPRISING GROUPS IN TABLE III AND FIGURE 3

TABLE V

PROBABILITY OF SELECTED SAMPLES FROM DDH-3 BELONGING TO DIFFERENT FLOWS

TABLE VI

PROBABILITIES THAT GROUP MEMBERS WOULD DEVIATE IN ABUNDANCES FROM GROUP MEANS AS MUCH AS UNKNOWN SAMPLES FROM DDH-3

TABLE VII ABUNDANCES IN CHEMICALIY ANOMOLOUS REGIONS OF DH-4 
This study had a threefold purpose: (1) to examine the atomic absorption gamma spectroscopy, emission spectroscopy, and neutron activation data accumulated by Atzantic Richfield Hanford Company through 1976 (predecessor company to Rockwell Hanford Operations), and evaluate the precision of the data and their calibration reliability; (2) to determine from these chemical data those elements that were best for characterizing basalt flows for correlation purposes; and, (3) to use these chemical data to establish statistical correlations among type locality reference groups and the basalt flows penetrated by deep core holes in the Pasco Basin or exposed on the surface at certain field section Zocations.

Evaluation of the atomic absorvtion data indicates that most $\mathrm{K}_{2} \mathrm{O}, \mathrm{Na}_{2} \mathrm{O}$, $\mathrm{SiO}_{2}, \mathrm{TiO}_{2}, \mathrm{FeO}, \mathrm{Al}_{2} \mathrm{O} 3$, and $\mathrm{CaO}$ were measured with a precision of better than 4 percent, but MgO measurements were less precise (v6 percent). Calibration differences for these oxides were usually within 3 percent of those obtained by other laboratories. Evaluation of neutron activation analysis data indicates that $\mathrm{Cr}$, Co, Sc, La, and Sm were alz measured with a precision better than 6 percent. Calibration differences for these elements were commonly about 10 per percent. Long-term variations in precision occurred for some atomic absorption analyses and some neutron activation analyses.

Samples from Core Holes $D D H-1, D H-2, D D H-3, D H-4$, and $D H-5$ were compared with the type locality reference groups to determine if correlations could be established statistically using the data. Overall, 90 percent of the basalt core samples in DDH-3, DH-4, and DH-5 down to the level of the Priest Rapids IV could be statistically correlated, and for many the correlations were nearly unambiguous. Statistical correlation of basalts below the Priest Rapids IV level were more ambiguous because of the overall greater chemical similarity of these basalts. A satisfactory correlation of these units by chemical measurements alone could very likely be achieved from accurate and precise measurements on the elements considered in this study and the incorporation of additional trace elements (such data are currently being obtained). In practice correlations of basalt units below the Priest Rapids IV have been obtained using a combination of petrography, wireline geophysics, paleomagnetics, and chemical variations of selected elements. 


\section{CONCLUSIONS}

\section{OVERALL QUALITY OF THE CHEMICAL DATA}

Most of the atomic absorption data examined as part of this study were measured for $\mathrm{K}_{2} \mathrm{O}, \mathrm{Na}_{2} \mathrm{O}, \mathrm{SiO}_{2}, \mathrm{TiO}_{2}, \mathrm{FeO}, \mathrm{Al}_{2} \mathrm{O}_{3}$, and CaO with a precision of better than 4 percent. This value includes flow inhomogeneities, as well as measurement uncertainties. Longterm variations caused by changes in analytical procedures or techniques were generally less than 3 percent ( 1 sigma value), but CaO (5 percent), $\mathrm{TiO}_{2}$ ( 8 percent), and, possibly, $\mathrm{K}_{2} \mathrm{O}$ ( 6 percent) were exceptions. The overall calibration for these oxide values was good and usually gave values within 3 percent of those obtained by other laboratories. Mgo, however, was measured with less precision than the other oxides and its overall calibration was about 11 percent different than that obtained by other laboratories. $\mathrm{Ba}$, as measured by atomic absorption, gave values which were about 130 parts per million too high. The precision of the Ba measurement is unknown, because of possible flow inhomogeneities. The above comments for all of the elements apply to the general body of data, but there were a number of examples of apparently bad values for most of the atomic absorption measurements.

The quality of the neutron activation analysis data depended strongly on the element being measured. Na was done as well by neutron activation analysis as by atomic absorption, while Fe was not. Cr, a very important element for characterization, Co, Sc, La, and Sm were all measured with a precision of better than 6 percent. Eu was measured somewhat less precisely. Long-term variations were generally better than 4 percent for all of the elements just discussed, although that for $\mathrm{Cr}$ could not be determined. Notable exceptions were $\mathrm{Sm}$ and $\mathrm{La}$, which had very large apparent changes in calibration from one sample group to another. Therefore, these elements were not used in the characterization despite their high precision of measurament. 
Differences of 10 percent betwcen the overall calibration of the trace element analyses in this report and those from other laboratories were common.

\section{CHEMICAL CHARACTERIZATIONS OF INDIVIDUAL BASALT UNITS}

The most important elements for basalt characterization, as shown by these analyses, were: Cr, a trace element measured by neutron activation analysis; and, secondly, Fe, a major element as measured by atomic absorption (as mentloned below, this was unexpected for $F e)$. The next most important elellenls were: $\mathrm{Sc} ; \mathrm{Eu} ; \mathrm{K}$; $\mathrm{Mg}$; and, Ti; followed closely by $\mathrm{Ba}, \mathrm{Ca}, \mathrm{Co}, \mathrm{Al}$, and $\mathrm{Na}$. The least useful was Si.

The gamma spectroscopy data and emission spectroscopy data were generally not useful for characterization purposes because. of low precision and erroneous values.

\section{CHEMICAL CORRELATIONS OF INDIVIDUAL BASALT UNITS}

Statistical comparisons of analyses from the type locality groups of analyses with basalt core samples are adequate to assign correlations for about 90 percent of the basalt core samples from Core Holes DDH-3, DH-4, and DH-5 down to the level of Priest Rapids IV. These units include Ice Harbor I, Ice Harbor II, Ward Gap, Elephant Mountain, Pomona, Gable Mountain (Esquatzel), Huntzinger, and Priest Rapids IV. The correlations are very prominent and the flow assignments are nearly unambiguous when trace and minor, as well as major, element abundarices are available. The prominence of the correlations also indicates that the general character of the core holu chemirni data for Core Holes $\mathrm{DDH}-3, \mathrm{DH}-4$, and $\mathrm{DH}-5$ down to the Priest Rapids IV level is comparable to that of the type locality data. The correlations of these units in Core Holes $\mathrm{DDH}-1$ and $\mathrm{DH}-2$ were more ambiguous because useful trace element data were not available. Correlations of basalt units stratigraphically 
between the Priest Rapids IV and the Vantage Sandstone are considerably more ambiguous. The High Mg, Grande Ronde Basalt in Core Holes DH-4 and DH-5 occurring immediately below the Vantage Sandstone correlates well with the Museum and Rocky coulee type locality groups. Generally, the other Grande Ronde Basalt units do not correlate with any of the type locality groups, but this is to be expected, inasmuch as type locality data for units stratigraphically below the Rocky Coulee flow were not included in this study.

Correlations in this study were established using statistical procedures alone applied to a set of geochemical analyses. These correlations agree with other previously derived correlations based on visual and graphical comparisons of the same analyses. Correlations having an even higher reliability can be established using statistical procedures such as those given in this report in conjunction with known stratigraphic relationships and with geophysical, petrographic, and paleomagnetic data.

The nearly unambiguous chemical correlations (down to the level of Priest Rapids IV) among the core holes, field sections, and type locality reference groups, when considered in terms of the relative stratigraphic sequence of the units, is evidence for their overall lateral continuity and lateral chemical homogeneity and limited post-emplacement chemical change, even over areas of hundreds of square miles.

\section{STRATIGRAPHIC LIMITATIONS OF RESULTS}

Because of the data limitations at the initiation of this study, the results contained in this report are aimed toward emphasizing geochemical relationships within the upper few flows of the total basalt stratigraphy section in the Pasco Basin, primarily the upper Yakima basalt. Additional data have recently been obtained for the middle and lower Yakima basalt, 
particulariy the lower Yakima basalt in Core Holes DDH-3, DH-4, and $\mathrm{DH}-5$. These additional data consist of major element compositions measured by X-ray fluorescence analysis, a more accurate and precise method than the atomic absorption techniques evaluated in this work. The type of study described in this report should be repeated with the inclusion of the new data.

\section{INTRODUCTION}

\section{PURFOSE}

In the development of nuclear energy, an area of great importance concerns the safe final storage of nucleal wastes: 'The feasibility of storing such wastes in mined caverns in the basalt layers of the Columbia River Basalt Group has been the subject of an extensive on-going study. (1) To guarantee the integrity of the stored material over periods of time long enough to allow its radioactivity to decay to acceptable levels, it is necessary to evaluate water migration through interflow zones and the extert of isulaliul afforded by the flow interinrs. An important facet in such studies is the identification, correlation, and riappiny of the basalts, both in the vertical and horizontal directions. To this end, a considerable corpus of geophysical, petrographic, and chemical data was accumulated by the Atlantic Richfield Hanford Company and its successor, Rorkwell Hanford operations, from core holes and from many surface nutrirops. The present study was undertaken for the purpose of statistically evaluating the basalt chemical data accumulated by Rockwell Hanford operations and determining their usefulness for identifying and correlating basalt units.

\section{GENERAL GEOLOGY}

The Columbia River Basalt is a layered mass of more than 200,000 cubic kilometers of tholeiitic lavas covering an area of more than 150,000 square kilometers in parts of washington, 
Oregon, and Idaho (Figure 1). This mass of basalt represents the accumulation of repeated eruptions from middle Miocene (approximately 16 million years before present) through late Miocene (approximately 8 million years before present) that filled a slowly subsiding basin shaped planoconvex downward in cross section. An estimated 80 percent of the volume of the columbia River Basalt was emplaced during a 3-million-year volcanic pulse between 16 million years before present and 13 million years before present.

In the Pasco Basin, near the center of the area covered by the Columbia River Basalt, the total thickness of the columbia River Dajalt io a minimum of approximately 1,500 meters.

Between 1968 and 1972,4 core holes were drilled in the Pasco Basin. These core holes are roughly located at the corners and center of a 500-square-mile square in the Pasco Basin (Figure 1). The basalt flows penetrated by these core holes were correlated using geochemical, petrographic, and geophysical data collected from core samples of individual flows, and using known stratigraphic relationships from within the Pasco Basin and from the region. These correlations form the basis for the current model of the basalt stratigraphy in the Pasco Basin. (1)

\section{BASALT STRATIGRAPHY}

The approximate ages, stratigraphic positions, and descriptions of the rocks within the Pasco Basin are summarized in Figure 2. The stratigraphic chart is under revision, but, for purposes of this discussion, it is used in its present form. The Columbia River Basalt Group is subdivided into five formations. The upper three formations (the saddle Mountains - upper Yakima, the Wanapum - middle Yakima, and Grande Ronde - lower Yakima) collectively constitute the Yakima Basalt subgroup. These formations are, in turn, subdivided into various members and flows. The lower two formations, the Imnaha and Picture Gorge, are not currently known in the Pasco Basin. 
TYPE LOCALITIES (T.L.) AND FIELD SECTIONS (F.S.) 1 ICE HARBOR T.L.

WARD GAP T.L.

POMONA T.L.

GABLE MOUNTAIN

HUNTZINGER T.L.

PRIEST RAPIT

REZATINEL GAP T.L.

SENTINEL GAP T.L.

GINKGO T.L.

ROCKY COULEE T.L.

SILLUSI BUTTE F.S.

SELAH BUTTE F.S.

BLAIR POINT F.S.

8 RUSH CANYON F.S.

19 YELLEPIT POND F.S

TYPE LOCALITY NAMES ARE INFORMAL, CURRENTLY UNDER REVISION

(a) CORE HOLES

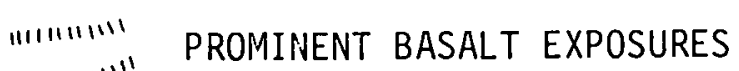
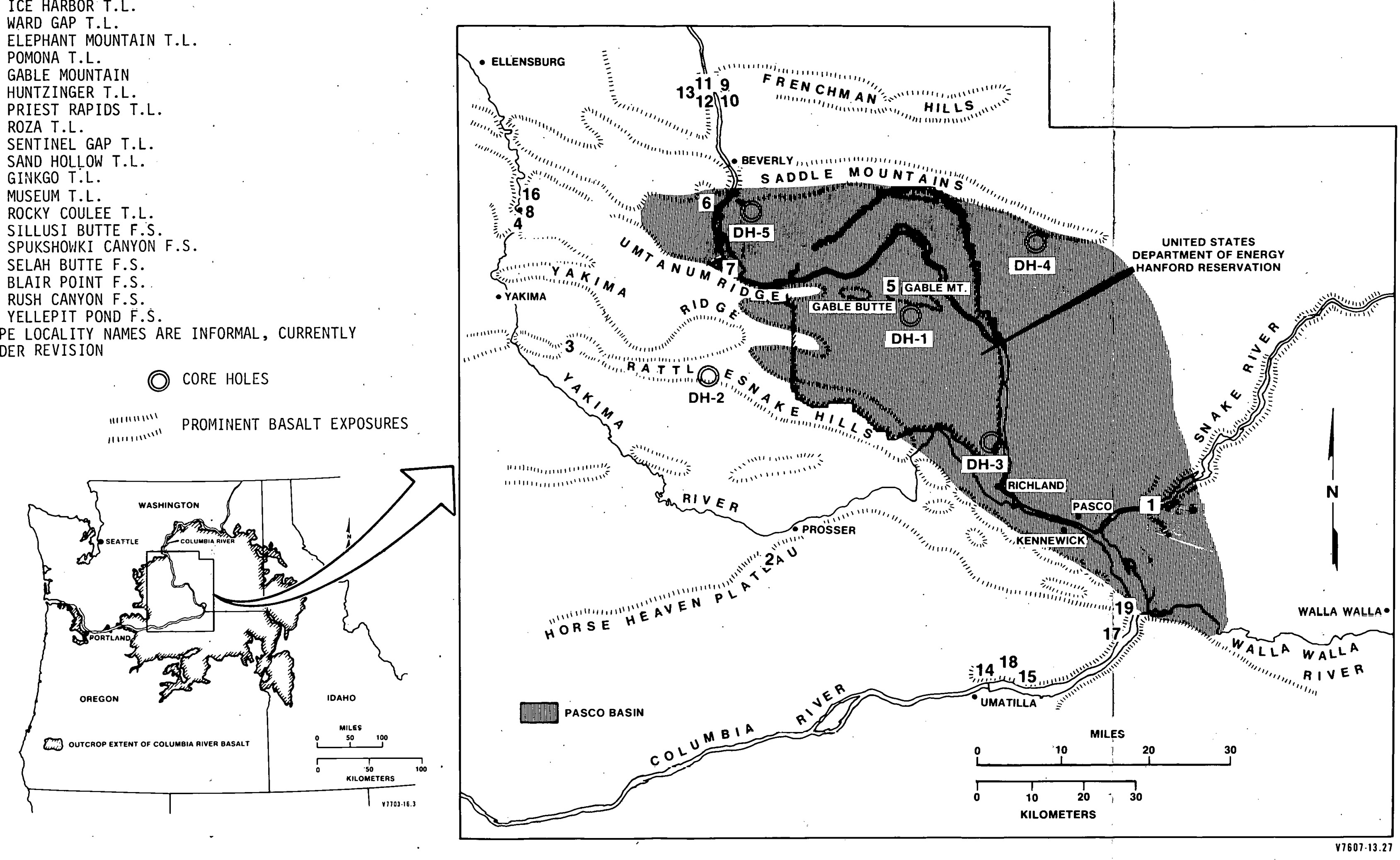

FIGURE 1 


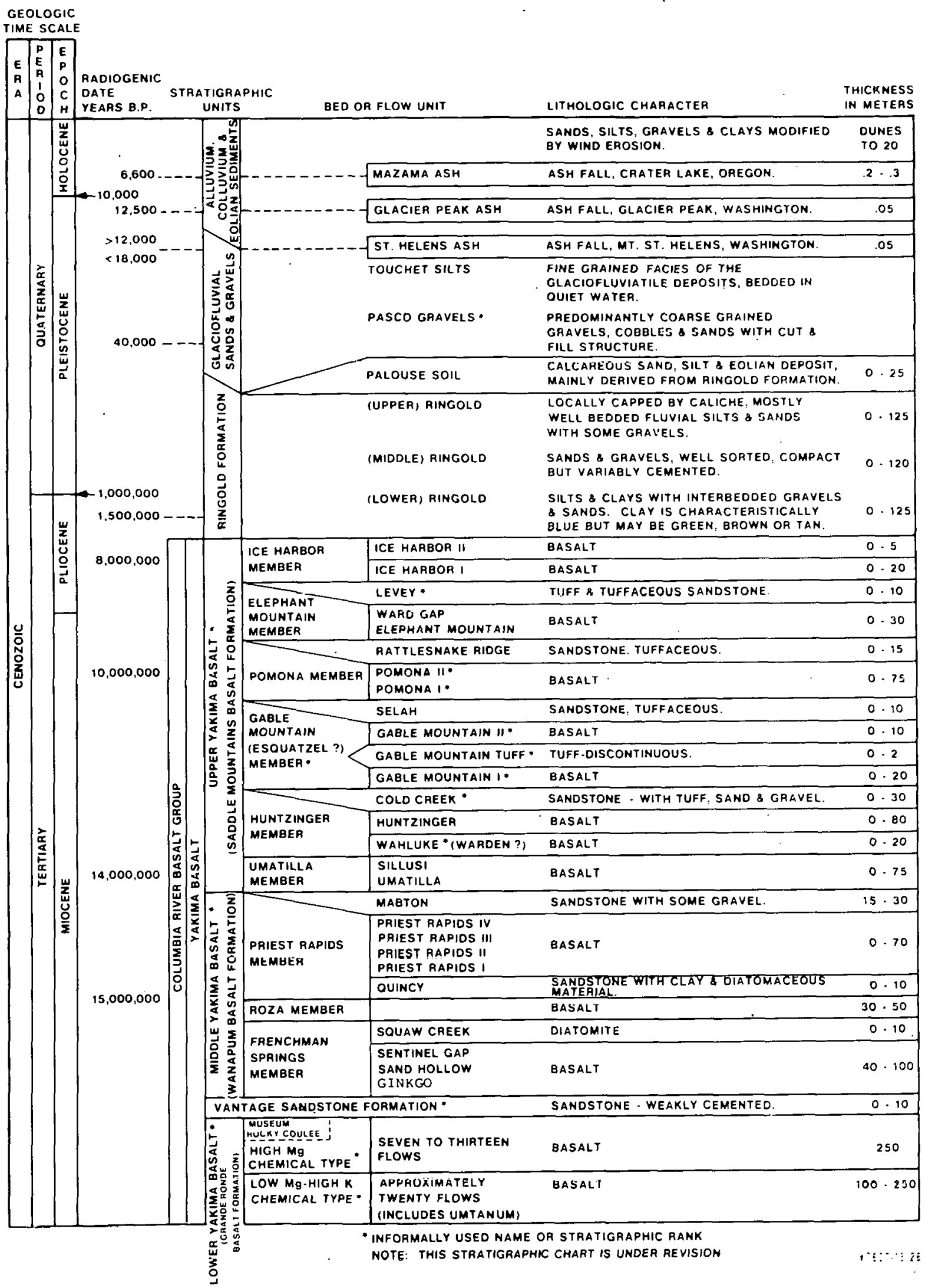

\section{FIGURE 2}


The Wanapum and Saddle Mountains basalts occur stratigraphically above the Vantage Sandstone and are divided into nine members. Each member consists of one or more individual basalt flows. The Grande Ronde Basalt flows occur stratigraphically below the Vantage sandstone and can be divided into at least two stratigraphic units on the basis of marked differences in chemistry. The lowermost unit, the Low Mg-High K Chemical Type, consists of at least 20 flows identified in Core Holes $\mathrm{DH}-4$ and DH-5. The uppermost unit, the High Mg Chemical Type, consists of 7 to 13 flows, alsu identified in DH-4 and DH-J.

The Saddle Mountains and Wanapum basalts contain some laterally extensive units covering hurdseds uf syuare kiloniteless wherein chemical variations are related to stratigraphic position. In the Grande Ronde Basalt, much less is known concerning the nature of intra- and inter-flow chemical variations and the lateral extent or shape of individual flows.

\section{SOURCE OF DATA}

The Rockwell Hanford Operations' data supplied for use in this study were from the following sources:

Type Locality Data

Volume I, Page 43, ARH-ST-137; (1)

Field Section Data

Volume II, Pages $B-1$ to $B-42, A R H-S I-13 \% ;$ (1)

Core Hole Data

Volume II, Pages $\mathrm{C}-1$ to $\mathrm{C}-103$, AKH-S'I-137; (1.)

and

ARH-2610.

In addition, non-Rockwell Hanford Operations' data were also used. $(3,4,5)$ 
EVALUATION OF CHEMICAL DATA

The chemical data evaluated here are principally from type locality and field section samples because more data were available from these for cross-checking different analytical techniques. The different analytical techniques used were: atomic absorption; ncutron activation analysis; gamma ray spectrometry; and, emission spectroscopy.

Atomic absorption was used for the major elements with the results expressed as abundances of $\mathrm{SiO}_{2}, \mathrm{Al}_{2} \mathrm{O}, \mathrm{FeO}, \mathrm{MgO}, \mathrm{Na}_{2} \mathrm{O}$, $\mathrm{CaO}, \mathrm{K}_{2} \mathrm{O}$, and $\mathrm{TiO}_{2}$. Barium and other minor elements were sometimec measured; bit those measurements were not evaluated.

Neutron activation analysis was used on many samples. Abundances of $\mathrm{Na}, \mathrm{La}, \mathrm{Sm}, \mathrm{Fe}, \mathrm{Co}, \mathrm{Sc}, \mathrm{Cr}, \mathrm{Eu}$, Th and Hf were measured for most samples, and abundances of $\mathrm{Tb}$ and $\mathrm{Ta}$ on $\mathrm{a}$ lesser number.

Gamma ray spectrometry was used on many samples to determine abundances of ${ }^{40} \mathrm{~K},{ }^{228} \mathrm{Th}$, and ${ }^{226} \mathrm{Ra}$ that can be used to calculate the abundance of $\mathrm{K}, \mathrm{Th}$, and $\mathrm{U}$.

Emission spectroscopy was used for a number of samples; $\mathrm{Ba}$, $\mathrm{Cr}, \mathrm{Ni}, \mathrm{Rb}, \mathrm{Sc}, \mathrm{Sn}, \mathrm{V}, \mathrm{Zr}$, and, sometimes, $\mathrm{Zn}$ were measured.

\section{ANALYTICAL TECHNIQUES AND S'I'A'TISTICAL PROCEDURES}

(In this work, precision refers to the root-mean-square deviations of a group of measurements of the same material, presumably made in the same laboratory over a short period of time. Generally, only measurement.s nf different rocks were available and these, therefore, gave an upper limit of the precision. Also, a concordance between groups of samples and the laboratories which analyzed them was not available. It is, therefore, assumed that measurements of samples with sample numbers close to each other were made in the same laboratory at about the same time. Some apparent exceptions to the assumption are noted.) 
All calculations used in this work were made using Lawrence Berkeley Laboratory computer facilities.

1. One of the most effective methods of data evaluation was a comparison of the abundances of a given element as measured on the same samples by different techniques; e.g., Na as measured by atomic absorption and by neutron activation analysis. The ratio of these values (expressed as either the elemental or oxide abundances) should be equal to one within the experimental uncer... tainties. If one or both of the techniyuts ale imploperly calibrated, but the calibrations are consistent throughout a group of data, then the ratio will be consistently different from one. Variations in the ratio reflect short-term or long-term errors in measurement. A comparison of the apparent precisions of measurement for two different techniques and the precision in their individual ratios can determine, in favorable cases, source variations as well as the actual measurement for edch Lëlnique.

2. The root-mean-square deviation of the averages of measurellents of yroups of samplcs is one mothod of determining a calibration variation which presumably takes place over a relatively long period of time. If the aveiaye of ratios of mcajurcmentc by different techniques for different sites are themselves averaged, and lie root-mean-square deviation determined, this latter value should be appreciably better than its overal. root-mean-square deviation. If not, then it is an indication of calibration variations.

3. Where measurements of the same element of the same samples by different techniques are not available, comparisons were sometimes made between different elements which are chemically similar. For example, 
if the precision of measurement were much better for Hif: than for $\mathrm{Zr}$, there was assumed to be a problem in the $2 \dot{r}$ measurement.

4. Another type of comparison was made with measurements, from other laboratories; :i.e., the: U. S. Geological. Survey: and the Lawrence Berkeley Laboratory. Data used from the U. S. Geological survey came from two publications. One was as open file report (3) which was used because it includes a large number of individual analyses which permitted calculation of root-mean-square deviations. The other. was a journal publication that contained average values for major: element compositions. (4) These latter values may be. more accurate as they conform to the U. S. Geological Survey standards. The Lawrence Berkeley Laboratory. data are unpublished, but appear in the form of graphs: in a: Lawrence Berkeley Laboratory report. (5) Comparisons with other laboratories determine upper limits: for: calibration errors for specific units.. If both U. S. Geological Survey and Lawrence Berkeley: Laboratory agree, and Rockwell Hanford operations: does: not, the Rockwell Hanford operations:' measurements are: assumed to have a calibration error. The variation: in this error over a number of units is a long-term: calibration variation.

5. When samples from different areas appear to belong to the same unit from geophysical and stratigraphic arguments and from most of their chemical abundances; large deviations. from the overall mean of the abundances of a specific element at a given site are regarded as suspicious: When the site behaves: the same way for two or more units, there is assumed to be a: calibration error in the measurements for that site. 
RESULTS

Precisions of measurements (or limits) and calibration variations (or limits) for the various elements and oxides are summarized in Table I. The relative value for characterization purposes of the elements and oxides found to be useful is shown in Table II in terms of a Figure of Merit. Omitted from Table II are $\mathrm{Na}$ and $\mathrm{Fe}$ determined by neutron activation analysis because oxide percentages of the elements determined by atomic absorption are of higher precision for $\mathrm{Fe}$ and comparable precision fior Na. In addition, Sm and La were determined to have unacceptable calibration variations and Th values were unreliable; therefore, they are also omitted from this table.

The Figure of Merit in Table II was calculated using the following procedure. For each element (except Ba), the limits of precision and the calibration variation shown in Table I were combined by taking the square root of the sum of the squares, which gave an overall percentage uncertainty. This was multiplied by the average abundance of the element in the range considered which gave an uncertainty in the Rockwell Hanford Operations' data in percent or parts per million. The range of variatiun for each element shown in Volume I, rage 43, ARH-ST-137(1) from the flows with the second highest to the second lowest abundances was divided by this uncertainty and resulted in the Figure of Merit shown in Table II. The Ba uncertainty was. calculated by combining the 42 parts per million calibration variation with 11 percent of the average abunaance in the range considered.:

As can be seen in Table II, $C r$ is found to be the most usetul element. Fe is the second most useful, although bet ler measurements of $\mathrm{Eu}, \mathrm{Mg}, \mathrm{Ti}$, and $\mathrm{K}$ and, possibly, Sc and Ba might make them comparable. $\mathrm{Si}$ is the least useful element in the existing data, but more reliable values might improve its usefulness : considerably. 


\section{TABLE I}

SUMMARY OF EVALUATION OF ROCKWELL HANFORD OPERATIONS CHEMICAL DATA

Precision

of Measurement ${ }^{a}$

Calibration

Variation ${ }^{b}$

Rockwell Hanford Operations and others

Atomic Absoiption

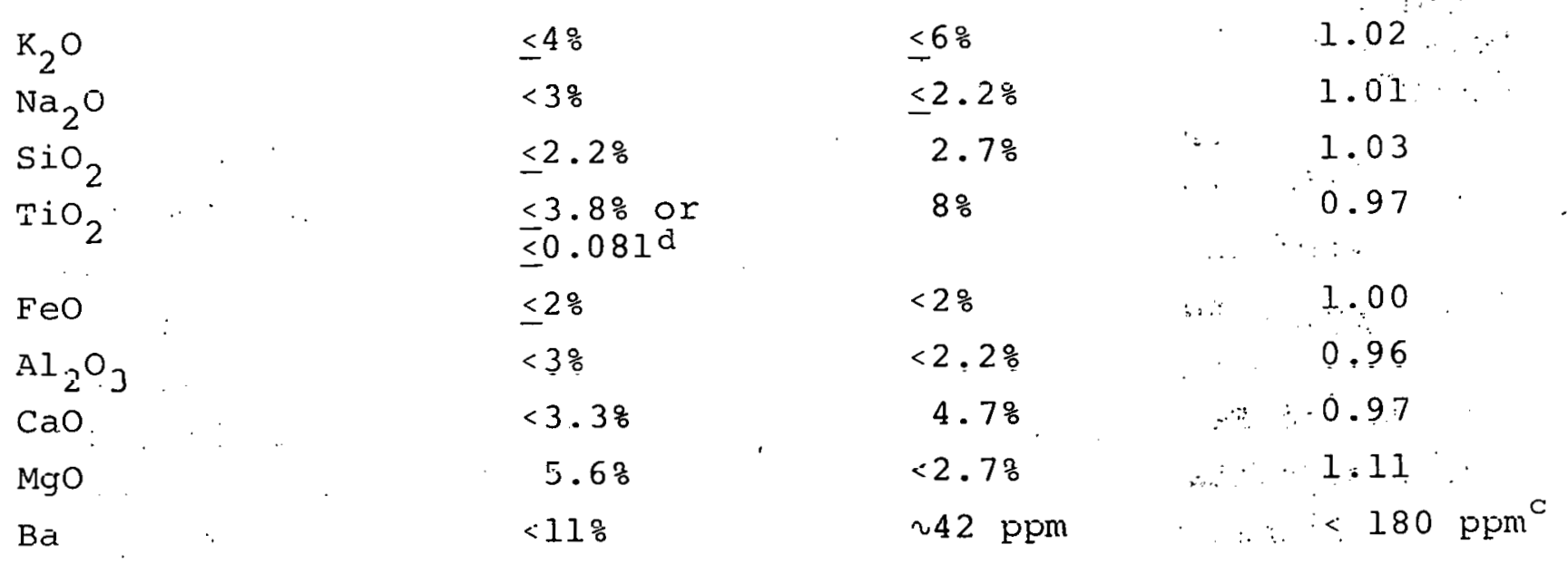

Neutron Activation Analysis

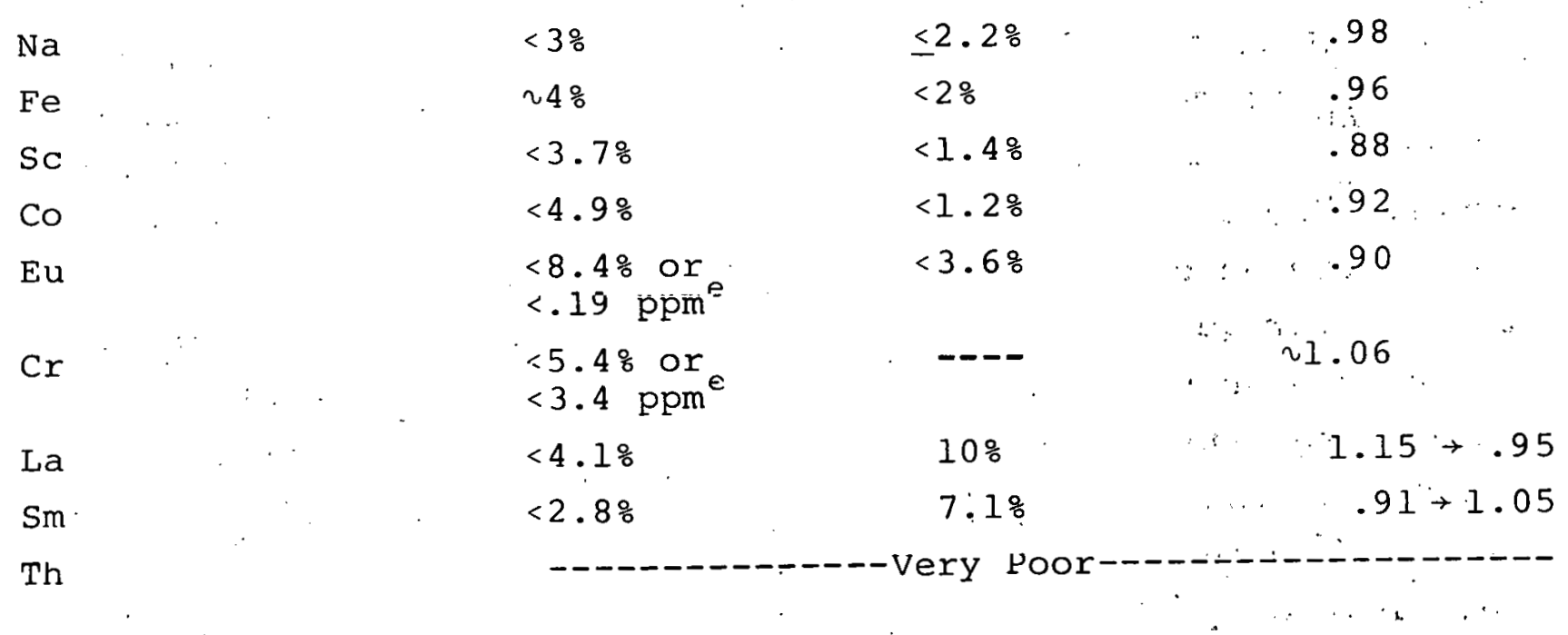

${ }^{a}$ Standard deviation expressed as percent of the mean, except for $\mathrm{TiO}_{2}$ which is also expressed in absolute percent.

${ }^{\mathfrak{b}}$ Standard deviation expressed as percent of the mean, except for $\mathrm{Ba}$ whirh is expressed in absolute amounts (parts per mililion).

${ }^{c}$ Rockwell. Hanford Operations minus others $=180$ parts per million. For:small $\mathrm{TiO}_{2}$ abundances the precision is <0.081 absolute percent.

${ }^{e}$ Precision of measurement is the larger of the two values. 


\section{TABLE II}

\section{USEFULNESS OF VARIOUS ELEMENTS \\ AS MEASURED BY ROCKWELL HANFORD OPERATIONS \\ FOR BASALT CHARACTERIZATION}

Oxide or Element

Measured by Rockwell

Hanford Operations

Method

$\sin 2$

$\mathrm{Na}_{2} \mathrm{O}$

$\mathrm{Al}_{2} \mathrm{O}_{3}$

Co

$\mathrm{CaO}$

$\mathrm{Ba}$

$\mathrm{TiO}_{2}$

$\mathrm{MgO}$

$\mathrm{K}_{2} \mathrm{O}$

$\mathrm{Eu}$

Sc

Feo

$\mathrm{Cr}$
AA

$A A$

$A A$

NAA

$A A$

$\mathrm{AA}$

AA

$A A$

AA

$N A A$

NAA

AA

NAA
Figure of Merit For Characterization

2.7

3.9

4. 4

5.2

5.6

6.5

7.7

8.4

8.9

10.1

10.5

$12.8^{\mathrm{a}}$

34

a This is an unexpectedly high Flgure of Merit, Fco analyses of basalts in Lhe wanapum dild Grandr. Ronde basalts have such high within-flow variations that they appear to be of limited usefulness for basalt characterization. 
Details of the results of the evaluation of the Rockwell Hanford Operations' atomic absorption, neutron activation, gamma spectroscopy, and emission spectroscopy data are available upon request from the Waste Isolation Program Library.

\section{TYPE LOCALITY CHARACTERIZATION}

STAT ISTICAL PROCEDURES

The mean abundances and root-mean-square deviations of the 13 elements determined to be most useful for basalt characterization (Table II) are shown in Table III. This includes 19 type locality groups ${ }^{(1)}$ and a group composed of samples from spukshowki Canyon, Blair Point, Yellepit Pond, and Selah Butte. The Umatilla type locality group also includes samples from spukshowki Canyon, Bl,air Point, Yellepit Pond, and Mound Pond. The groups are in the same order as shown in ARH-ST-137, (1) except for the Umatilla and Wahluke groups. Table IV shows the concordance of groups. and Rockwell Hanford Operations' samples.

For nearly all groups, the root-mean-square deviations were calculated with the equation:

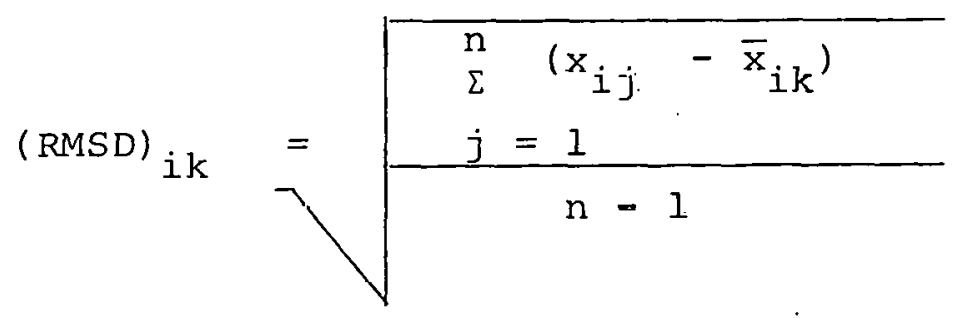

where $x_{i j}$ is the abundance of element $i$ in rock $j, \bar{x}$ is the mean value of the abundance of element $i$ for the group $k$, and $n$ is the number of group members. In each calculation, the resulting (RMSD) $i k$ werc compared with minimum values deduced from the preceding section, and the larger was tabulated. The minimum root-mean-square deviation values used for Table III were the following: $\mathrm{SiO}_{2}-3.5$ percent; $\mathrm{Al}_{2} \mathrm{O}_{3}-3.6$ percent; FeO - 2.8 percent; MgO - 7.2 percent; $\mathrm{CaO}-5.4$ percent; $\mathrm{Na}_{2} \mathrm{O}-3.9$ percent; 


\section{TABLE III}

TYPE LOCALITY GROUP

\begin{tabular}{|c|c|c|c|c|}
\hline ICE & ICE & & & ELEPHANT \\
\hline HARBOR III & HARBOR I & WARD & GAP & MOUNTAIN \\
\hline
\end{tabular}

Major Elements

(In Percent)

$$
\begin{aligned}
& 49.1 \pm 1.7 \quad 48.4 \pm 1.751 .1 \pm 1.8 \quad 50.0 \pm 1.8 \\
& 11.3 \pm .4 \quad 12.7 \pm .512 .8 \pm .5 \quad 12.5 \pm .4 \\
& 16.3 \pm .513 .6 \pm .414 .6 \pm .6 \quad 13.8 \pm .4 \\
& 4.6 \pm .36 .9 \pm .54 .6 \pm .344 . \overline{3} \pm . \overline{3} \\
& 9.0 \pm .5 \quad 10.5 \pm .68 .2 \pm .49 .5 \pm .1 .4 \\
& 2.53 \pm .15 \quad 2.30 \pm .14 \quad 2.50 \pm .10 \quad 2.54 \pm .22 \\
& 1.12 \pm .09 \quad .75 \pm .07 \quad 1.13 \pm .09 .1 .26 \pm .10 \\
& 3.4 \pm .3 \quad 3.1 \pm .32 .80 \pm .25 .3 .6 \pm .3 .
\end{aligned}
$$

\begin{tabular}{|c|c|c|c|c|c|c|c|c|c|c|}
\hline Sc & & 39.0 & \pm & 1.6 & 42.0 & \pm 1.7 & 30.0 & \pm 1.7 & 33.0 & \pm 1.3 \\
\hline $\mathrm{Eu}$ & & 5.4 & \pm & .5 & 3.3 & \pm .3 & 2.83 & \pm .26 & 2.90 & \pm .26 \\
\hline $\mathrm{Co}$ & & 39.0 & \pm & 2.0 & 45.0 & \pm 2.2 & 41.7 & \pm 2.1 & 48.0 & \pm 2.4 \\
\hline $\mathrm{Ba}$ & & 27.45 & \pm & 112 & 837 & \pm 75 & 614 & \pm 55 & 771 & \pm 69 \\
\hline $\mathrm{Cr}$ & . & 40 & \pm & 4 & 62 & \pm 6 & 23.0 & \pm 2.3 & 27.0 & \pm 2.7 \\
\hline Ave. & 13 Elem & ents & & $.4 \frac{7}{8}$ & & $5 \%$ & & $.4 \%$ & & $2 \%$ \\
\hline RMSD & Best 12 & Elements & & $.0 \%$ & & $2 \%$ & & $.1 \%$ & & $6 \%$ \\
\hline
\end{tabular}

Trace and Minor Elements (Parts Per Million) 
TABLE III (continued)

$\underline{\text { POMONA }}$ ROZA $\quad \begin{gathered}\begin{array}{c}\text { SENTINEL } \\ \text { GAP }\end{array} \\ \text { HOLLOW }\end{gathered}$

Major Elements

(In Percent)

$\begin{array}{lrrrrrrr}\mathrm{SiO}_{2}^{+\mathrm{a}} & 50.7 \pm 1.8 & 51.8 \pm 1.8 & 52.9 \pm 1.9 & 52.8 \pm 1.8 \\ \mathrm{Al}_{2} \mathrm{O}_{3} & 14.4 \pm .5 & 13.1 \pm .5 & 12.8 \pm .5 & 12.6 \pm \pm .5 \\ \mathrm{FeO} & 10.8 \pm .3 & 14.3 \pm .4 & 14.4 \pm .4 & 13.7 \pm \pm .4 \\ \mathrm{MgO} & 7.8 \pm .6 & 4.9 \pm .4 & 4.5 \pm .3 & 4.8 \pm \pm .3 \\ \mathrm{CaO} & 10.0 \pm .5 & 8.0 \pm .4 & 7.5 \pm .4 & 8.0 \pm \pm .4 \\ \mathrm{Na}_{2} \mathrm{O} & 2.42 \pm .09 & 2.77 \pm .11 & 2.78 \pm .11 & 2.85 \pm .11 \\ \mathrm{~K}_{2} \mathrm{O} & .68 \pm .11 & 1.20 \pm .10 & 1.26 \pm .10 & .97 \pm .08 \\ \mathrm{TiO}_{2} & 1.58 \pm .14 & 2.53 \pm .23 & 2.62 \pm .23 & 2.57 \pm .23\end{array}$

Trace and Minor Elements (Parts Per Million)

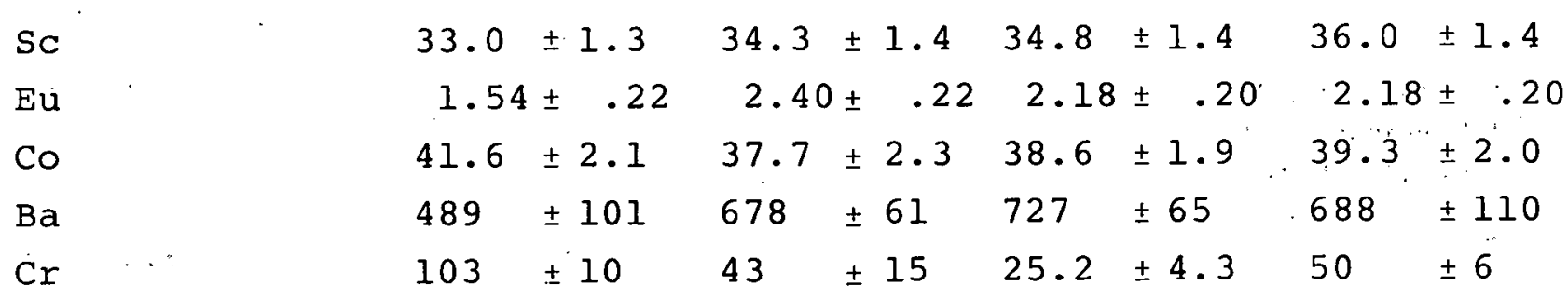

Ave. 13 Elements $\quad 8.1 \% \quad 8.2 \% \quad 6.7 \%$. $6.9 \%$

$\begin{array}{lllll}\text { RMSD Best } 12 \text { Elements } 7.0 \% & 6.0 \% & 5.9 \% & 6.2 \%\end{array}$


TABLE III (continued)

GINKGO $\quad$ MUSEUM $\begin{array}{r}\text { ROCKY } \\ \text { COULEE }\end{array}$

Major Elements

(In Percent)

$\begin{array}{lllllll}\mathrm{SiO}_{2}^{+\mathrm{a}} & 51.1 \pm 1.8 & 54.0 \pm 1.9 & 53.5 & \pm 1.9 & 52.6 . \pm 1.8 \\ \mathrm{Al}_{2} \mathrm{O}_{3} & 12.9 \pm .5 & 13.9 \pm 1.5 & 13.4 \pm .5 & 13.0 \pm .5 \\ \mathrm{FeO} & 14.7 \pm .4 & 10.8 \pm .8 & 10.8 \pm \pm .3 & 13.9 \pm \pm .8 \\ \mathrm{MgO} & 4.4 \pm .3 & 5.0 \pm .5 & 4.9 \pm .4 & 4.1 \pm . .3 \\ \mathrm{CaO} & 7.6 \pm .4 & 8.0 \pm .4 & 8.0 \pm .4 & 7.7 \pm \pm .5 \\ \mathrm{Na}_{2} \mathrm{O} & 2.74 \pm .09 & 2.80 \pm .11 & 2.82 \pm .15 & 2.67 \pm .10 \\ \mathrm{~K}_{2} \mathrm{O} & 1.10 \pm .16 & .95 \pm .08 & .96 \pm .09 & 1.68 \pm .19 \\ \mathrm{TiO}_{2} & 2.62 \pm .23 & 1.65 \pm .15 & 1.70 \pm .15 & .2 .5 \pm \pm .23\end{array}$

Trace and Minor Elements (Parts Per Million)

$\begin{array}{lcccccccccc}\mathrm{Sc} & 34.4 \pm 1.4 & 34.0 & \pm 1.4 & 33.0 & \pm 1.3 & 28.7 & \pm 2.1 \\ \mathrm{Lu} & 2.26 \pm .21 & 2.6 & \pm .15 & 1.54 \pm & \pm 14 & 2.37 & .22 \\ \mathrm{Co} & 37.4 & \pm 1.9 & 39.0 & \pm 2.0 & 34.6 & \pm 1.7 & 43.0 & \pm 2.2 \\ \mathrm{Ba} & 712 & \pm 79 & 686 & \pm 62 & 671 & \pm 60 & 695 & \pm 63 \\ \mathrm{Cr} & 25 & \pm 7 & 56 & \pm 22 & 48 & \pm 14 & 7.5 & 1.1\end{array}$

Ave. 13 Elements

$8.5 \%$

$9.0 \%$

$7.8 \%$

$8.5 \%$

RMSD Best 12 Elements

$6.5 \%$

$6.5 \%$

$6.1 \%$

$6.8 \%$ 
TABLE III (continued)

$\underline{\text { HUNTZINGER }} \underline{\text { IV }}$. III

Major Elements

(In Percent)

$\begin{array}{lrrrrrr}\mathrm{SiO}_{2}^{+\mathrm{a}} & 52.0 \pm 1.8 & 58.9 \pm 2.2 & 50.3 \pm 1.8 & 50.3 \pm 1.8 \\ \mathrm{Al}_{2} \mathrm{O}_{3} & 15.2 \pm .5 & 12.7 \pm . .5 & 12.3 \pm .4 & 12.2 \pm \pm .4 \\ \mathrm{FeO} & 10.6 \pm .3 & 14.4 \pm .8 & \pm 5.3 \pm .8 & 14.2 \pm \pm .4 \\ \mathrm{MgO} & 6.9 \pm .5 & 6.1 \pm .4 & 4.5 \pm .4 & 4.8 \pm \pm .3 \\ \mathrm{CaO} & 8.9 \pm .5 & 8.2 \pm .4 & 7.6 \pm .5 & 8.3 \pm 1.0 \\ \mathrm{Na}_{2} \mathrm{O} & 2.44 \pm .10 & 2.40 \pm .09 & 2.52 \pm .19 & 2.53 \pm .10 \\ \mathrm{~K}_{2} \mathrm{O} & 1.00 \pm .08 & .85 \pm .07 & .94 \pm .15 & .97 \pm .08 \\ \mathrm{TiO}_{2} & 1.62 \pm .14 & 2.72 \pm .24 & \pm .92 \pm .26 & 2.97 \pm .26\end{array}$

Trace and Minor Elements (Parts Per Million)

$\begin{array}{lcccccccc}\mathrm{Sc} & 27.6 \pm 1.1 & 27.0 \pm .15 & 38.0 \pm 1.6 & 36.7 & \pm 1.5 \\ \mathrm{Eu} & 1.76 \pm .21 & 2.70 \pm .25 & 2.82 \pm .26 & 2.80 \pm & .27 \\ \mathrm{Co} & 41.4 \pm 2.1 & 40.0 \pm 2.0 & 39.4 \pm 2.0 & 38.0 \pm 1.9 \\ \mathrm{Ba} & 557 \pm 50 & 688 & \pm 179 & 612 & \pm 55 & 611 & \pm 55 \\ \mathrm{Cr} & 175 & \pm 17 & 86 & \pm 9 & 14 & \pm 4 & 16 & \pm 2\end{array}$

Ave. 13 Elements

$6.4 \%$

$7.8 \%$

$8.9 \%$

$6.9 \%$

RMSD Best 12 Elements $6.0 \%$

7. $3 \%$

6.43 
TABLE III (continued)
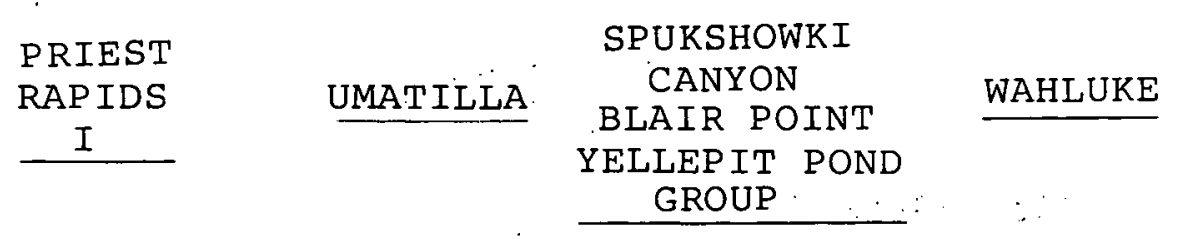

Major Elements

(In Percent)

$\begin{array}{lrrrrrr}\mathrm{SiO}_{2}^{+\mathrm{a}} & 51.4 \pm 1.8 & 55.3 \pm 1.9 & 51.0 \pm 1.8 & 53.2 \pm 1.9 \\ \mathrm{Al}_{2} \mathrm{O}_{3} & 12.2 \pm .8 & 13.3 \pm .5 & 13.1 \pm .5 & 13.6 \pm \pm .5 \\ \mathrm{FeO} & 15.0 \pm .6 & 12.4 \pm .7 & 14.3 \pm .4 & 12.2 \pm .3 \\ \mathrm{MgO} & 4.6 \pm .4 & 2.9 \pm .4 & 4.5 \pm .3 & 5.3 \pm .4 \\ \mathrm{raO} & 7.7 \pm .4 & 5.8 \pm .3 & 7.8 \pm .4 & 8.1 \pm .4 \\ \mathrm{Na}_{2} \mathrm{O} & 2.57 \pm .10 & 3.22 \pm .18 & 2.76 \pm .18 & 2.80 \pm .11 \\ \mathrm{~K}_{2} \mathrm{O} & 1.00 \pm .17 & 2.67 \pm .22 & 1.42 \pm .21 & 1.90 \pm .15 \\ \mathrm{IiO}_{2} & 2.93 \pm .26 & 2.41 \pm .21 & 2.67 \pm .24 & 1.80 \pm .16\end{array}$

Trace and Minor Elements (Farts Pel Million)

$\mathrm{Sc}$

$38.0 \pm 1.5 \quad 25.1 \pm 1.6 \quad 34.0 \pm 1.4 \quad 25.5 \pm 1.0$

$\mathrm{Eu}$

$$
2.75 \pm .25
$$

$4.2 \pm .4$

$2.19 \pm .20$

$2.05 \pm .19$

Co

$$
39.5 \pm 2.0
$$

$25.9 \pm 2.1$

$37.5 \pm 2.1$

$37.5 \pm 1.9$

$\mathrm{Ba}$

$$
65
$$

$3544+319$

$690 \pm 98$

$1115 \pm 100$

$\mathrm{CI}$

$13.5 \pm 1.4$

8

$\pm 4$

2.4

+. 1

$36 . \pm 7$

Ave. 13 Elements

$7.3 \%$

$9.9 \%$

$7.8 \%$

$6.9 \%$

RMSD Best 12 Elements $6.5 \%$

$7.2 \%$

$6.1 \%$

$5.9 \%$ 


\section{TABLE IV}

\section{ROCKWELL HANFORD OPERATIONS' BASALT SAMPLES COMPRISING GROUPS IN TABLE III AND FIGURE: 3}

1. Ice Harbor II

2. Ice Harbor I

3. Ward Cap

4. Elcphant Mountain

5. Pomona

6. Gable Mountain

7. Huntzinger

8. Priest Rapids IV

9. Priest Rapids III

10. Priest Rapids II

11. Priest Rapids I

12. Roza

13. Sentinel Gap

14. Sand Hollow

25. Ginkgo

16. Museum

17. Rocky Coulee

18. Umatilla (Includes samples from Sillusi Butte, Rush Canyon, Yellepit-Mound Pond, and Blair Point)

19. Group Formed Principally From Spukshowki Canyon Rocks (But some from Blair Point, Yellepit Pond, and selah Bulle

20. Wahluke
A-1424

No $\mathrm{Sc}, \mathrm{Eu}$, Co or $\mathrm{Cr}$ $A-1426, A-1427$

A-1425

No Sc, Eu, Co or $\mathrm{Cr}$ A- 1423

A-1276, A-1277, A-1278

A-1393

No Sc, Eu, Co or $\mathrm{Cr}$

A-1394, A-1395, A-1396, A-1397

$A-1266, A-1267, A-1268, A-1269$. $A-1270$

A-2017, A-2018, A-2019

No $\mathrm{Sc}, \mathrm{Eu}, \mathrm{Co}$ or $\mathrm{Cr}$

$\mathrm{A}-1037, \mathrm{~A}-1038, \mathrm{~A}-1039$

$A-1301, A-1302, A-1303, A-1304$, A-1305

$\mathrm{PR}-01, \mathrm{PR}-02, \mathrm{PR}-21, \mathrm{PR}-22$

PR-04, PR-05, PR-08, PR-23，PR-24

PR-09, PR-10, PR-11

PR-12，PR-13，PR-27A

$A-1279, A-1280, A-12 B 1$

$K-5032, K-5033, K-5034, \cdot K-5035$, K5036

$\mathrm{K}-5001, \mathrm{~K}-5002, \mathrm{~K}-5003, \mathrm{~K}-5005$, $K-5007, K-5009$

$\mathrm{K}-5012, \mathrm{~K}-5014, \mathrm{~K}-5015, \mathrm{~K}-5017, \mathrm{a}$ $\mathrm{K}-5020$

$\mathrm{K}-5010, \mathrm{~K}-5011$

$K-5025, K-5026, K-5027, K-5028$, $\mathrm{K}-5029$

$A-1237, A-1230, A$ 1239, $\lambda-12 R 3$ $A-1254, A-1255, A-1256, A-1175$, $A-1236, A-1235, A-1261, A-1262$, $A-1263, A-1264, A-1265$

No SC, Eu, Co or $\mathrm{Cr}$ $A-1214, A-1215, A-1216, A-1217$, $A-1221, A-1220, A-1219, A-1348$, A-1236

$A-1177, A-1178, A-1179, A-1180$, $A-1181, A-1183, A-1253, A-1252$, $A-1251, A-1250, A-1249, A-1248$, $A-1204, A-1203, A-1202, A-1234$

No Sc, Eu, Co or $\mathrm{Cr}$ $A-1210, A-1209, A-1208, A-1207$, $A-1206, A-1205, A-1298, A-1297$, $A-1296$

$A-4016, A-4017$ 
$\mathrm{K}_{2} \mathrm{O}-8.1$ percont; $\mathrm{TiO}_{2}-8.9$ percent; Sc -4.0 percent; Eu -9.1 percent; Co - 3.0 percent; $\mathrm{Ba}$ - 9 percent; $\mathrm{Cr}$ - 10 percent. The $\mathrm{Ba}$ and $\mathrm{Cr}$ values are estimates determined from the data evaluation discussed in the preceding section.

The $\mathrm{SiO}_{2}^{+}$values are the abundances of $\mathrm{SiO}_{2}+\mathrm{MnO}+\mathrm{P}_{2} \mathrm{O}_{5}+$ $\mathrm{SrO}+\mathrm{BaO}+$ trace elements. These values were found in the data evaluation to be somewhat more reliable than the $\mathrm{SiO}_{2}$ data and could be determined from the other major element and volatility measurements.

As seen in Table III, the average (by squares) of the root-mean-square deviations of all. 1.3 elements ranges between 6.4 percent and 9.9 percent. If the worst element were discarded, then the average root-mean-square deviation ranges from 5.9 percent to 7.2 percent. As these values include measurement errors, the flows in the localities sampled may be even more homogeneous. Thus, each flow has a definite chemical composition pattern with a small variation for a certain group of elements.

The next step was to determine if these groups are sufficiently different from each other to make unambiguous assignments of flow origin. One sample was selected from each group and it was usually the first sample in the chart in Volume I, Page 43, ARH-ST-137(1) which had measurements of trace elements. The elemental abundances of samples were compared with each group and a root-mean-square index of the agreement was determined with the following equation:

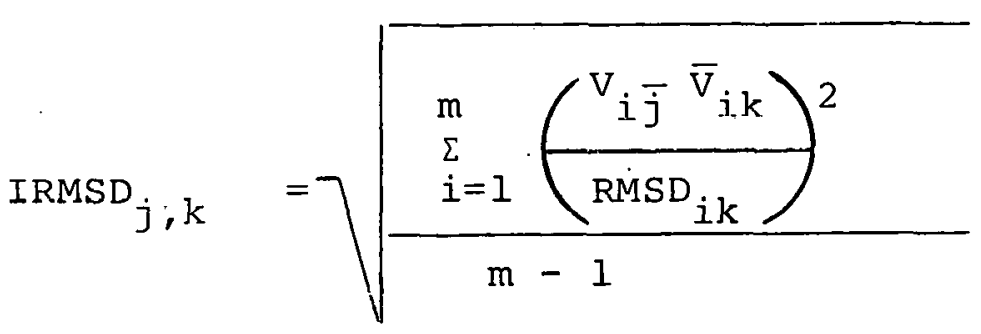


where $V_{i} \bar{j}$ is the abundance of element $i$ in the sample $j, \bar{v}_{i k}$ is the average abundance of element $i$ in the group $k, R^{2} D_{i k}$ is the root-mean-square deviation of element $i$ in group $k$, and $m$ is the number of elements used in the calculation. This calcuilation was made for each value of $j$ and each value of $k$. Before discussing the values which were obtained, a brief discussion of their significance is worthwhile. If sample $j$ is a member of group $k$, if group $k$ is large enough that RMSD $i k$ has small errors, and if $m$ is very large, then $\operatorname{IRMSD}_{j, k}$ should equal 1 . If $j$ is not a member of group $k$, then IRMSD ${ }_{j, k}$ should be larger than 1 .

In a practical situation, the number of rocks used in forming a type locality group may be quite small and the uncertainty in the RMSD $i, k$ would be significant:

$$
\sigma\left(\operatorname{RMSD}_{i, k}\right) \sim \operatorname{RMSD}_{i, k} / \sqrt{2(n-1)}
$$

where $\mathrm{n}$ is the number of rocks comprising group $\mathrm{k}$. Exroneously small values of RMSD $_{i, k}$ (because of the small number of samples) could then inflate IRMSD $_{i, k}$ considerably. The use of minimum. $\mathrm{RMSD}_{i, k}$ to reduce this effect tends to depress the values of IRMSD $_{j, k}$ considerably even below I. As an example, if the minimum root-mean-square deviation were chosen correctly, in a: group comprising 26 rocks, the root-mean-square index for group members would be .87 and would be rather insensitive to the number of rocks in the group. The error in root-mean-square index, however, is very sensitive to the number of elements in sample $j$ used in the calculation, and this uncertainty is: $\sqrt{\mathrm{m} / 2}($ IRMSD * $(\mathrm{m}-1))$.

This factor is pertinent to the number of elements used in the comparison between a sample and a group. In the example given above for 13 elements, the uncertainty in root-mean-square index would be 0.24 . As a test, the abundances of 24 samples of the Umatilla group were compared with their group elemental averages and root-mean-square deviations in the fashion. 
described above. The average of the 24 values of the root-meansquare was 0.85 and the root-mean-square deviation in the values was .29 which is consistent with theoretical expectations. A cut-off of 1.5 on the value of root-mean-square indexes will be used in the next section in the comparisons between borehole rocks and reference groups. Only $\sim 1$ percent of the group members would be expected to have a root-mean-square index as large as 1.5 .

\section{RESUL'TS}

The comparisons (root-mean-square index values) between the individual type locallty sallples aid the vagious type looality groups are shown in Figure 3. A dashed line is placed in each drawing to indicate the root-mean-square index of 0.7. For Groups 1 and 2 in Figure 3, only one trace element analysis was available. Thus, there is zero deviation for each of the trace elements and only the major elements contribute to the root-meansquare index. Thcse root-mean-square indexes then are anomolously low for the group members. In general, fur the small number of samples comprising most groups, the root-mean-square indexes are smaller than the $0.8 \mathrm{~b}$ mentioned eariier. This arises as the minimum root-mean-square deviation (for each element) used in the calculation contains not only uncertainties duc to rock inhomogeneity and instrumental precision errors which would appear in the small groups, but also calibration variations which generally would not appear in such groups. It was necessary to include these in the calculations because measurements of borehole samples discussed in the next section were made at a different time and possibly in different laboratories. There are no ambiguities in assignment of the first 8 samples (A-1424 to PR-01) in Figure 3, as in each case the rock agrees well with one group; i.e., root-mean-square index $<1$, and all other groups have root-mean-square index $>1.5$. It should be pointed out that this is an analysis of groups as measured by Rockwell Hanford operations

- and not of flows. In the following section, the significance of these groups with respect to flows will be discussed. 

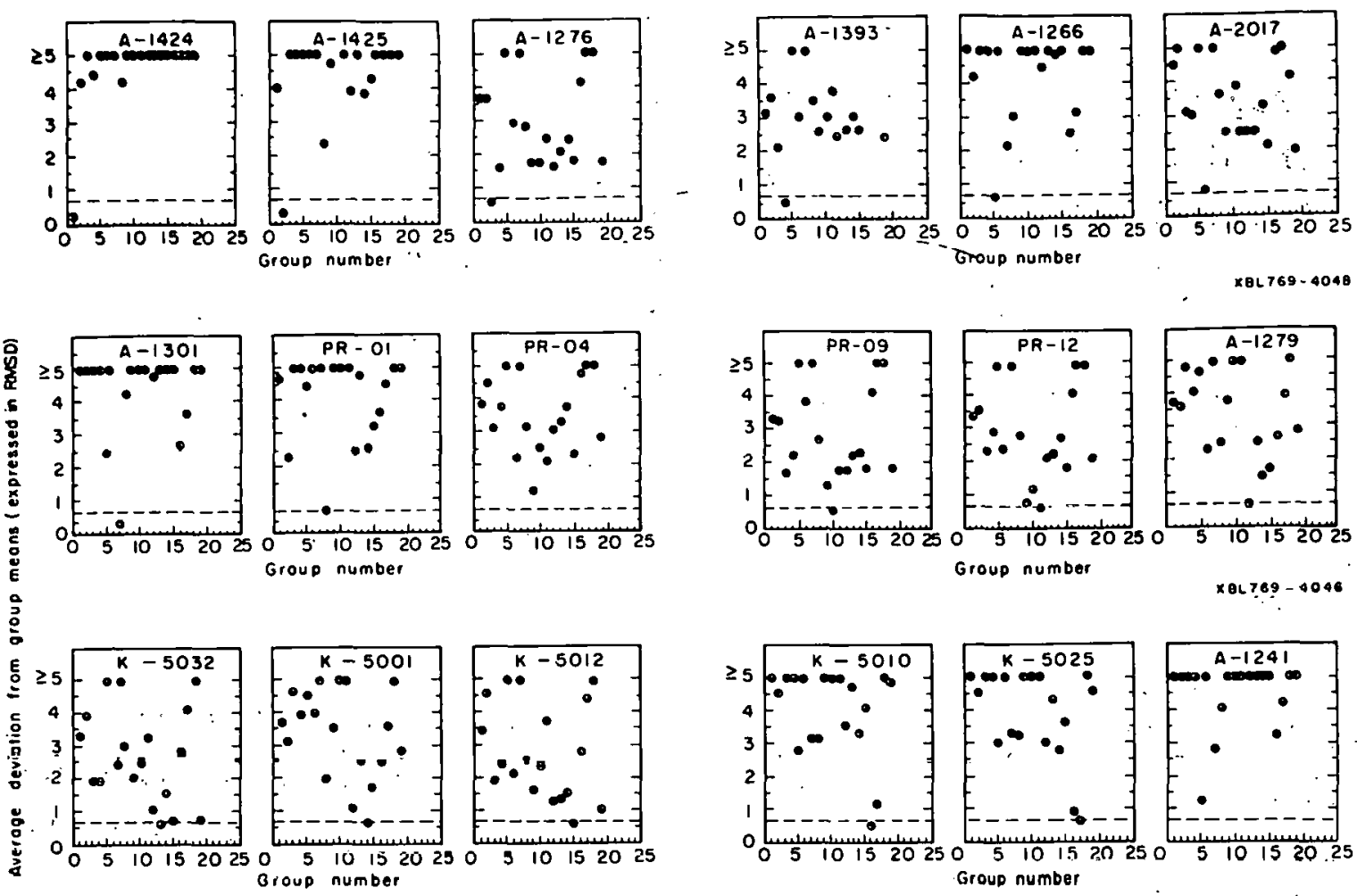

$x 86769-4047$
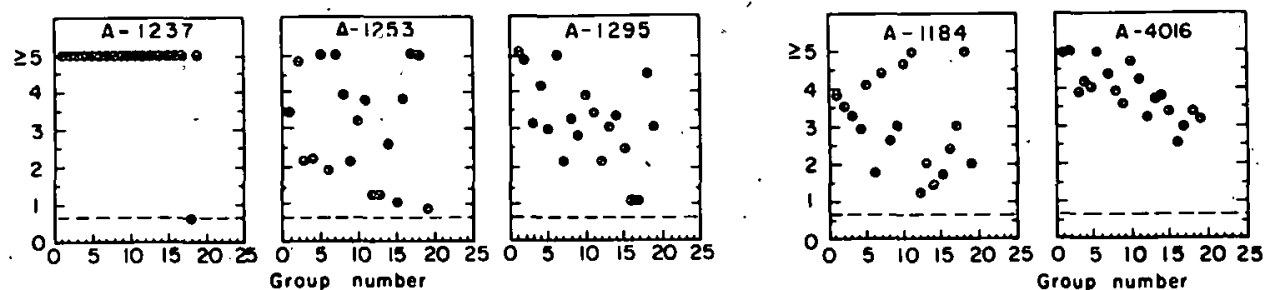

$\times 047199-4049$

\begin{tabular}{|c|c|c|c|}
\hline $\begin{array}{c}\text { Rock } \\
\text { Designation }\end{array}$ & Source & $\begin{array}{c}\text { hock } \\
\text { Designation }\end{array}$ & Source \\
\hline$n-19,74$ & Tepe Harbor II & $k-5032$ & Sentinel Gap \\
\hline$A-1425$ & Ice Harbor I & $K-5001$ & Sand Hollow \\
\hline A-1276 & ward Gap & $k-5 n 12$ & Cinkigo \\
\hline$A-1393$ & Elephant Mountain & $k-5010$ & Museum \\
\hline$A-1266$ & Pomona & $K-5025$ & Rocky Coulee \\
\hline$A-2017$ & Gable Mountain & $A-1241$ & Sillusi Butte \\
\hline$A-1301$ & Huntzinger & $A-1237$ & Sillusi Butte \\
\hline PR-01 & Priest Rapids iv & $A \cdot 1253$ & Spokshowki Canyon \\
\hline $\begin{array}{l}P R-04 \\
P R-09\end{array}$ & $\begin{array}{l}\text { Prinst Rapids III } \\
\text { Priust Rapids.JI }\end{array}$ & $A-1295$ & $\begin{array}{l}\text { Selah Butte } \\
\text { (Only Major } \\
\text { Elements) }\end{array}$ \\
\hline $1, H-12$ & Pricist Rapids I & $A-1184$ & Blair Poont \\
\hline$n-1<79$ & Roya & $A-4016$ & $\mathrm{DH}-4$ \\
\hline
\end{tabular}

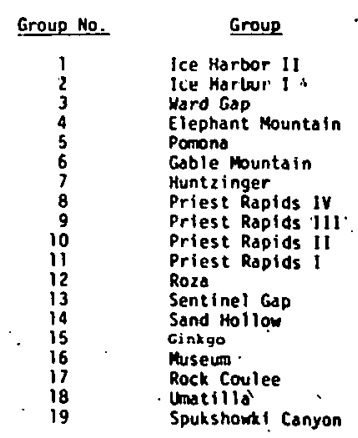

FIGURE 3

TYPE LOCALITY SAMPLE VERSUS TYPE LOCALITY GROUP COMPARISONS 
Figure 3 shows rocks whose correlation is uncertain from the chemical data. PR-04 could belong to Group 9 (Priest Rapids I), PR-09 could belong to Groups 9 or 10 (Priest Rapids III or II), and PR-12 could belong to Groups 9, 10, or 11 (Priest Rapids III, II, or I). Rock A-1279 agrees with the Roza, even though it may have an erroneous $\mathrm{Cr}$ measurement. This possible $\mathrm{Cr}$ error may be contributing an unnecessarily large root-mean-square deviation to the $\mathrm{Cr}$ value for the Roza group and allow some rocks to agree in composition with Roza which otherwise would be eliminated.

In Figure 3, Rock K-5032 agrees with Roza (Group 12), ... Sentinel Gap (Group 13), and Ginkgo (Group 15). It also agrees with Group 19, a group made up of rocks (from Spukshowki Canyon and other sites) which were found directly under the Umatilla. Rock K-500l agrees with both Sand Hollow and Roza. Better and more extensive $\mathrm{Cr}$ measurements of the Roza group should remove this ambiguity. Rock K-5012 agrees with Roza, Sentinel Gap, Ginkgo, and Group 19. This is a reiteration of the effects mentioned for Rock K-5032. Rocks K-5010 and K-5025 agree with the Museum or Rocky Coulee. More data are needed for the Museum, especially Cr values. Rock A-124l from Sillusi Butte agrees with the Pomona. Rock A-1241 is representative of a group of rocks from Sillusi Butte, Rush Canyon, Spukshowki Canyon, and, possibly, selah Butte.

In Figure 3, Rock A-1237 obviously belongs to the Umatilla. Rock A-1253 aqrees with Group 19 and the same comments apply as for Rock K-5032. Rock A-1295 is from Selah Butte. It agrees with the kocky coulee and Museum groups, althuuyh unly lhẹ major elements are measured. Rock A-1184 is representative of a group of rocks from Blair Point occurring under Group 19. Rock A-1184 does not agree well with any of the 18 groups, although the root-mean-square index from the Roza is 1.27 . Because of significant errors in the Blair Point measurements, 
the assignment is uncertain. Rock A-4016 does not agree with any of the listed groups. It forms a group of its own, Wahluke, along with Rock $A-4017$ on the chart in Volume I, Page 43, ARH-ST-137. (1)

It again should be noted that this study arrived at correlations based solely on statistical evaluation of certain geochemical data. When the geochemical data are combined with paleomagnetic, geophysical, petrographic, and stratigraphic positions, many of the discrepancies are resolved.

\section{CORRELATIONS BETWEEN BOREHOLE SAMPLES AND REFERENCE SAMPLES}

\section{STATISTICAL PROCEDURE}

In the preceding section, it was shown that over half of the Rockwell Hanford operations' type locality groups of analyses (Volume I, Page 43, ARH-ST-137[1]) could be distinguished from each other by the existing chemical data alone. There were some ambiguities between the remaining groups, but these could be reduced by better or more extensive chemical measurements or other techniques such as wireline geophysics, paleomagnetics, or petrography. If all such ambiguities were removed, however, there would still remain the question as to the extent that the rather limited selections of rocks in each type locality group can identify flows at different geographic locations. 'l'his problem is affected by two main factors: the general extent of chemical homogeneity of the basalt flows at the time of emplacement; and, post-emplacement effects which may change composition.

Some of the previous measurements of the Pomona and Elephant Mourtain flows bear on the first factor. The 18 samples of the Pomona analyzed at Lawrence Berkeley Laboratory ${ }^{(5)}$ were collected by Dr. H. U. Schmincke from an area in excess of 5,000 square miles, and the 12 Elephant Mountain samples (also collected by Dr. Schmincke) were collected from an area in excess of 2,000 square miles. The average root-mean-square deviation of the abundances 
of 21 trace, minor, and major elements was 5.2 percent for the Elephant Mountain samples and 4.9 percent for the Pomona samples. These values are smaller than the Rockwell Hanford operations' values shown in Table III, but suggest the latter may be consistent with general flow variations over an extended area.

As a method of checking this premise and the general applicability of using these chemical measurements for flow identification, the Rockwell Hanford Operations' chemical data on cores from five core holes (Figure I) were examined. A method of analysis was employed that exploits the usefulness of the main body of chemical data without being greatly disturbed by occasional bad measurements. If the latter occur in only a few percent of the measurements, this can still cause frequent complications when 13 elements are being considered per sample. Each sample is compared with each type locality group, just as in the preceding section, except that one element is removed from the calculations. The rejected element is the one whose abundance deviates most from the group average when expressed in units of the root-meansquare deviation for that element in the group.

Some of the sensitivity for distinguishing between flows is lost, particularly when one element is reponsible for most of the distinctive chemical features of a flow. This is more than compensated by the increase in reliability of the assignments. If completely reliable data were used, this rejection of an element might probably not be necessary.

$\underline{\text { RESULTS }}$

The chemical abundance data for samples frrom Core Holes $\bar{D} \bar{D} \bar{H}-1$, $\mathrm{DH}=2, \mathrm{DDH}-3, \mathrm{DH}-4$ and $\mathrm{DH}-5$ were treated in the same fashion as the data on the individual type locality rocks in the preceding section. The value of root-mean-square index was calculated for each of 617 borehole rocks for each of 23 groups. Root-mean-square index, as discussed previously, is an index of the deviation of 
the abundances of a rock from a given chemical group. It will normally average $\sim .85$ for a group member, but there will be about a 1 percent probability that it will be as large as 1.50 and the latter value was chosen as a cut-off point for most of the data. The data are presented in graphic form in the figures in Appendix A. To facilitate reading the graphs, a variable $v$ is plotted which is equal to 1.50 minus the root-mean-square index. Thus, $v=0$ for values of the root-mean-square index which are equal to 1.50 or larger, and increasing values of $v$ show increasing correlations between samples and groups. The data from DDH-1 and DDH-3 will be discussed in detail to indicate the type of information which can be obtained from major elements alone (including $\mathrm{Ba}$ ) and with trace elements in addition. In the comparisons that follow, frequent reference is made to samples by sample number; e.g., CA-5 or A-5021. The exact location of these samples is given in the lithology logs of Volume II, ARH-ST-137. (i)

Although Core Holes $\mathrm{DH}-4$ and $\mathrm{DH}-5$ were both drilled to about 5,000 feet, the graphs for Core Hole DH-4 (Figures A-7 and $A-8$ in Appendix $A$ ) do not extend below 2,400 feet and the graphs for $\mathrm{DH}-5$ (Figures $A-9$ and $A-10$ in Appendix $A$ ) do not extend below 2,800 feet. The lower Yakima basalt flows below these depths have not been formally named at the member level, nor have type localities been assigned. They were not included in the Rockwell Hanford operations' type locality groups of analysis in Volume I, Page 43, ARH-ST-137. (1) Therefore, no comparisons were made among the deeper lower Yakima basalts and the Rockwell Hanford Operations' type locality groups.

\section{DDH-1 COMPÁRISUNS}

Figgure A-1 in Appendix A shows comparisons of samples from Core Hole DDH-1 with 8 type locality groups representing upper and middle Yakima flows. Eight major elements: $\mathrm{SiO}_{2} ; \mathrm{Al}_{2} \mathrm{O}_{3}$; $\mathrm{FeO}$; 
$\mathrm{MgO} ; \mathrm{CaO} ; \mathrm{TiO}_{2} ; \mathrm{Na}_{2} \mathrm{O} ; \mathrm{K}_{2} \mathrm{O}$; and, $\mathrm{Ba}$ are included in the analysis. No correlation between the samples and Ice Harbor I and II flows was observed. Ward Gap shows several correlations, but crude Cr data suggest that nearly all correlations, except the uppermost two, would be eliminated if good $\mathrm{Cr}$ data were available. The Elephant Mountain type locality group was not included in this analysis, as the major element data available for this unit appeared more questionable than those for the other type locality groups. A composite Elephant Mountain group, however, was formed with U. S. Geological Survey and Lawrence Berkeley Laboratory data wherein the abundance of each element was normalized to the calibration of the main body of Rockwell Hanford operations' samples with calibration factors determined in the data evaluation. As can be seen in Figure $A-1$ in Appendix A, the correlation of the uppermost two samples in DDH-I with this composite group is very high. Again, good $\mathrm{Cr}$ data would probably eliminate most of the other correlations. The next 4 basalt samples from. increasing depths in $\mathrm{DDH}-1$ all show no correlation with any group. For the next 2 samples ( $\mathrm{CA}-6-255$ feet and $\mathrm{CA}-7-265$ feet), the closest agreement is with the Pomona, although the overlap is small. This small overlap is to be expected here because the samples are from the vesicular flow top (Volume II, Page C-4, ARH-ST-137) (1) where compositional variations probably reflect alteration. The next qroup of 5 rocks is from below the vesicular top and correlate with the Pomona, except for one sample, CA-10 at 300 feet. The rocks from 475 to 600 feet correlate well with the Gable Mountain (Esquatzel), but 2 small correlations with Gable Mountain are at 200 feet and 1,100 feet: trace element analysis would likely also remove these ambiguities. The next 2 samples (610 and 615 feet) do not agree with any of the type locality groups and probably represent differentiated Huntzinger. 'I'wo of the next 3 rocks from 630 tu 660 Ieel correlate with the Huntzinger. The rock which disagrees, A-1041, is very similar chemically to the others, except for $\mathrm{Ba}$ and $\mathrm{K}_{2} \mathrm{O}$. 
This may represent a difference in flow composition or more likely, 2 bad measurements in 1 sample for which the procedures. used in the analysis cannot compensate. No correlations were observed for the Wahluke. At least 9 of the next 13 rocks correlate well with the Umatilla group. The other 4 all have very high. barium content, which is indicative of the Umatilla, and they also agree better with that group than any of the others. The next 2 rocks from 825 and 870 feet are from sedimentary interbeds and, thus, have essentially zero overlap with any of the type locality groups.

In Figure $A-2$ in Appendix $A$, comparisons are shown between the rocks from $D D H-1$ and $8 \mathrm{middle}$ and lower Yakima groups. The rocks from 925 feet to 1,115 feet show varying degrees of correlation with middle Yakima groups.

The middle Yakima groups (Priest Rapids, Roza, Sentinel-Gap, Sand Hollow, and Ginkgo) are chemically similar, overall, and cover the data base used in this study. Therefore, ambiguities. in correlation based only on the chemical data considered in this study were expected. Paleomagnetic properties, however, permit corfelations within this sequence: the Priest Rapids has a reversed polarity; the Roza is transitional; and, the sentinel Gap, Sand Hollow, and Ginkgo have a normal polarity. Petrographic differences are also found. In practice, therefore, a multicriteria approach is used.

\section{$\underline{D H-2}$ COMPARISONS}

The data from Core Hole $\mathrm{DH}-2$ are suspect because the material balance, which varies between 100.2 and 106.7 percent, is somewhat high. Thus, measurements of some elements or components are wrong. At least part of the errors should be in one or more of those elements whose abundances are larger than the material balance discrepancy; i.e., $\mathrm{SiO}_{2}, \mathrm{Al}_{2} \mathrm{O}_{3}, \mathrm{FeO}$ and $\mathrm{CaO}$. 
Elephant Mountain, Ward Gap, and Pomona are clearly defined in Figure $A-3$ in Appendix $A$, but the Umatilla is not. The high Ba values, characteristic of the Umatilla, occur in all core samples between 180 and 360 feet, but only 2 samples give a positive indication (Figure A-3 in Appendix A). This is due principally to differences in $\mathrm{FeO}$ and $\mathrm{CaO}$ (and $\mathrm{TiO}_{2}$ in 1 sample) between the core hole data and the Umatilla reference group. These differences may be related to the errors of measurement in DH-2 samples reflected by the material balance and, therefore, cannot be ascribed to source variations at this time. The comparisons of $\mathrm{DH}-2$ samples with other reference groups are shown in Figure A-4 in Appendix A. The Priest Rapids III, II, and I'groups are well defined, but cannot be distinguished from each other. There are other ambiguities in assignments, but crude $\mathrm{Cr}$ measurements indicate these would be greatly reduced if good $\mathrm{Cr}$ data were available.

\section{DDH - 3 COMPARISONS}

Trace elements, as well as major elements, were measured in most of the samples from Core Hole DDH-3. The improvement due to the inclusion of trace elements is obvious, as shown in Figure $A-5$ in Appcndix $\Lambda$, where the Ice Harbor I, Pomona, Gable Mountain, and Umatilla are unambiguously defined. There were no correlations between any rock from DDH-3 and the Ice Harbor II, Huntzinger, or Wahluke flows. This is not unexpected, however, because of the relatively restricted geographic distribution of these flows.

It is possible to calculate the possibility of an erroneous assignment if certain limitations or assumptions can be placed on the calculation. These are: first, the unknown rock, if it is a basalt, must conform to one of the type locality groups; second, uncertainties in the type locality values and in all measurements can be considered as Gaussian; and, third, there 
are no coherences of significance (larger than measuring errors) between the abundances of the different elements used in the calculation. A failure of the third assumption will not change the sense of the calculations, but will make low correlation events appear less improbable than they are. In this procedure, the probability is first calculated for each group and each rock that a group member will have abundances deviating from the group averages as much as the unknown rock. This is the degree to which the chemical profile of a given rock overlaps a given group. Thus, for each rock, the sum of all of the probabilities for the different groups is normalized to 1 , and the resulting value for each group represents the respertive probablility that the rock belongs to that group.

The overlap between a rock and its parent flow can be lower than expected if chemical alterations have affected the composition or if the type locality comparison group is not representative. of the flow. Usually, this will not affect the sense of the calculation unless the overlap becomes so small that it is comparable with accidental overlaps with other groups. In this work only, overlaps of $10^{-10}$ or larger for 13 elements are. considered significant.

As shown in Figure A-5 in Appendix A, core samples taken from depths of 490 to 615 feet in Borehole DDH-3 correlate well: with the Pomona. The relative probabilities of these samples belonging to the different type locality groups when 13 elements are used in the classification are shown in Table $V$. It is seen that the possibility of an erroneous assignment is less. than 1 in $10^{13}$ if the restrictions set on the calculation are valid. The uncertainty, however, in the value is probably at least three orders of magnitude. This type of treatment was also applied to samples which showed no correlation with any of the groups in Figure $A-5$ in Appendix A. The probability overlaps are tabulated in Table VI and are of the form: 


\section{TABLE V}

PROBABILITY OF SELECTED SAMPLES FROM DDH-3 BELONGING TO DIFFERENT FLOWS ${ }^{a}$

\begin{tabular}{|c|c|c|c|c|}
\hline $\begin{array}{l}\text { Sample Number } \\
\text { Depth (Feet) }\end{array}$ & $\begin{array}{c}A-2011 \\
500 \\
\end{array}$ & $\begin{array}{l}A-2012 \\
525 \\
\end{array}$ & $\begin{array}{l}A-2013 \\
-575 \\
\end{array}$ & $\begin{array}{c}A-2014 \\
615 \\
\end{array}$ \\
\hline \multicolumn{5}{|l|}{ Group } \\
\hline Ice Harbor II & $10^{-113}$ & $10^{-116}$ & $10^{-117}$ & $10^{-117}$ \\
\hline Ice Harbor I & $10^{-41}$ & $10^{-43}$ & $10^{-46}$ & $10^{-45}$ \\
\hline Ward Gap & $10^{-113}$ & $10^{-116}$ & $10^{-117}$ & $10^{-117}$ \\
\hline $\begin{array}{l}\text { Lepliálil } \\
\text { Mountain }\end{array}$ & $10^{-113}$ & $10^{-116}$ & $10^{-117}$ & $10^{-117}$ \\
\hline Pomona & 1 & 1 & 1 & 1 \\
\hline Gable Mountain & $10^{-113}$ & $10^{-116}$ & $10^{-11 /}$ & $10^{-11 \%}$ \\
\hline Huntzinger & $10^{-24 b}$ & $10^{-13 b}$ & $10^{-14 b}$ & $10^{-16 b}$ \\
\hline Umatilla & $10^{-113}$ & $10^{-116}$ & $10^{-117}$ & $10^{-117}$ \\
\hline Wahluke & $10^{-113}$ & $10^{-111}$ & $10^{-117}$ & $10^{-105}$ \\
\hline $\begin{array}{l}\text { Priest Rapids. } \\
\text { IV }\end{array}$ & $10^{-27}$ & $10^{-17}$ & $10^{-24}$ & $10^{-16}$ \\
\hline$I, I I, I I I$ & $10^{-113}$ & $10^{-116}$ & $10^{-117}$ & $10^{-117}$ \\
\hline Roza & $10^{-113}$ & $10^{-116}$ & $10^{-117}$ & $10^{-11.7}$ \\
\hline $\begin{array}{l}\text { Sentinel Gap/ } \\
\text { Ginkgo }\end{array}$ & $10^{-113}$ & $10^{-116}$ & $10^{-117}$ & $10^{-117}$ \\
\hline Sand Hollow & $10^{-79}$ & $10^{-60}$ & $1.0^{-75}$ & $10^{-58}$ \\
\hline $\begin{array}{l}\text { Rocky Coulee/ } \\
\text { Museum }\end{array}$ & $10^{-46}$ & $10^{-26}$ & $10^{-35}$ & $10^{-26}$ \\
\hline
\end{tabular}

Calculation assumes all distributions are Gaussian and basalt samples must belong to one of the listed flows. Thirteen elements were used in the calculation. The probability that Pomona type locality samples would have elements deviating from the group average as much as the unknown were: $2 \times 10^{-9} ; 7 \times 10^{-5}$; $6 \times 10^{-3}$; and, $10^{-2}$ for samples $A-2011, A-2012, A-2013$, and A-2014, respectively.

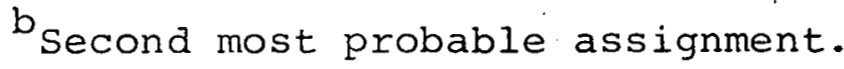


TABLE VI

PROBABILITIES ${ }^{\mathrm{a}}$ THAT GROUP MEMBERS WOULD DEVIATE IN ABUNDANCES
FROM GROUP MEANS AS MUCH.AS UNKNOWN SAMPLES FROM DDH-3 (Probability $=10^{-z}$ )

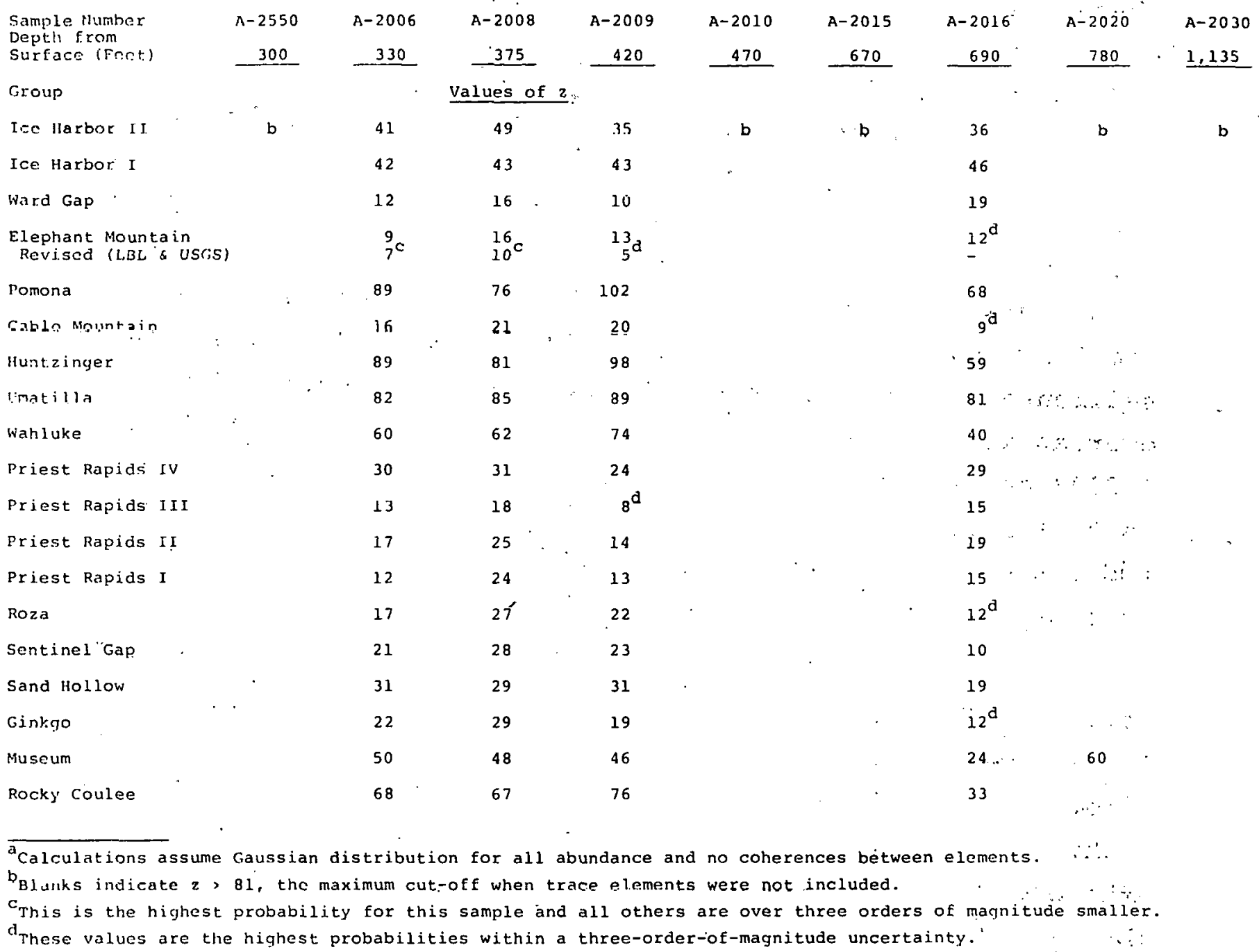




$$
\pi_{i}^{m-1}\left(\left(1-2 \int_{0}^{t_{i}} \frac{e \frac{-y^{2}}{2} d y}{\sqrt{2 \pi}}\right) ;\left(2 \int_{0}^{t} i \frac{e \frac{-y^{2}}{2} d y}{\sqrt{2 \pi}}\right)\right)
$$

where $m$ is the number of elements and $t_{i}$ is the deviation of element $i$ from the group average expressed in units of the group root-mean-square deviation for element $i$. The product, $\Pi$, is taken over m-l elements with the smallest factor. The maximum value for any factor is cut off at 1 . Values for the factors were taken from tables of the odds against the occurrence of deviations. (6) Revised values for the Elephant Mountain group, as discussed in the DDH-1 section, are included in liable VI. Samples A-2005, A-2010, A-2015, A-2020, and A-2030 are from sedimentary interbeds and, therefore, have essentially zero overlap with any reference groups. Samples A-2006, A-2008, and A-2009 agree best with the revised Elephant Mountain group. As this calculation may be uncertain to three orders of magnitude, the assignment of A-2009 from the chemical evidence alone is ambiguous, with priest Rapids III also being a possibility.

Figure $A-6$ in Appendix A shows the correlations between DDH- 3 and 8 groups of middle and lower Yakima basalts. The Priest Rapids IV assignment is unambiguous. For rocks taken from depths of 1,290 to 2,150 feet, assignments to other middle Yakima flows are not clear cut. As stated, this is because of the overall chemical similarity among middle Yakima basalts, but with the use of a multı-criteria approach 1ncluding paleomagnetics and petrography many of the correlation problems are regolved.

\section{$\underline{\text { DH- } 4 \text { COMPARISONS }}$}

Figures $A-7$ and $A-8$, in Appendix $A$ show the correlations between the DH-4 samples taken from depths of 2,400 feet or less and upper, middle, and some lower yakima groups. The revised Elephant Mountain abundances discussed in the section on $\mathrm{DH}-1$ were included. 
The trace element data in Volume II, Page C-55, ARH-ST-1:37(1) for sample A-4003 are different from those given by Tatman (2): and appear to have transfer errors. The Tatman data were usédin Figure A-7 in Appendix A. The top sample in DH-4 correlates viery well with the Elephant Mountain group, although the Ward Gap group has a small correlation. Measurements of higher reliability, including additional trace elements on ward Gap type locality material and on the core samples, might resolve this ambiguity. The next lower flow, Pomona, is very well defined. There appears some evidence for fractionation or alteration in the Huntzinger which will be discussed at the end of this section. The correlation with the Wahluke group is larger than proper, because the trace element measurements from the two DH-4 samples are the only ones available to form the reference group, and they are, coincidentally, nearly identical. The Umatilla is not detected and the next lower flow is Priest Rapids IV (Figure A-8 in Appendix A). The Priest Rapids III assignment looks moderately good, although there are small correlations with others. Nearly all of the other samples taken from the depths of 640 to. 1,470 feet correlate with either the Roza, Sentinel Gap, Sand Hollow, or Ginkgo groups, but, as stated previously, more extensive trace element data might reduce and possibly eliminate. some of these ambiguities. Samples, taken from depths of 1,500 to 2,180 feet correlate with the Museum and Rocky Coulee groups. More and better trace element data might also distinguish between them. The samples from 1,790 to 2,145 feet also correlate well with a group (now shown in the figures) of rocks from selah Butte for which only major element abundances were useful. This latter group comprised Samples A-1288 - A-1295 (Volume. II, Table V-VI, ARH-ST-137) (1) and was described as "flows of the high Mg chemical type" of the lower Yakima basalts (Volume II, Page B-27, ARH-ST-137). 
For 107 rocks below 2,180 feet, there were no correlations of significance for which both major and trace element data were useful, although 11 rocks ( 8 without trace element abundances) exhibited values of $v,(v=1.5$ - root-mean-square index) ranging from 0.01 to 0.37 . Although $\mathrm{DH}-4$ was drilled to a total depth of 4,776 feet (Volume II, Page C-102, ARH-ST-137), (1) the plots on Figure $A-8$ in Appendix $A$ do not extend below 2,500 feet, because of the lack of designated type localities for the deeper lower Yakima flows.

The region in $\mathrm{DH}-4$ between depths of 160 and 360 feet may be of geochemical interest. The abundances of all of the samples from this region are tabulated in Table VII. Two of the samples, A-4012 and A-4U13, which are called Gruup $B$ in the table, have a very similar chemical abundance pattern that is different from that of any of the reference groups. They are unusually abundant in $\mathrm{MgO}, \mathrm{Al}_{2} \mathrm{O}_{3}$, and $\mathrm{Cr}$ and unusually deficient in $\mathrm{K}_{2} \mathrm{O}$. There is no indication of this abundance pattern in data from any of the other 4 boreholes. Three samples, A-4010, A-4011, and A-4015, all have a similar chemical abundance pattern, and are called Group A in Table VII. The abundances of these samples can be mathematically related to the Huntzinger composition,. Group B composition, and the Wahluke composition. For example, if magma of the Huntzinger composition fractionated to give a 30 percent component with the Group B composition, the residue would have the composition of Group $A$. On the other hand, the A composition pattern can also be obtained by mixing the Huntzinger ( 60 percent) and Wahluke (40 percent) patterns. The Huntzinger is a geographically restricted unit. Petrologic characteristics, including possible reasons for these internal compositional variations within the Huntzinger, have been recently studied. (7) 


\section{TABLE VII}

ABUNDANCES IN CHEMICALLY ANOMOLOUS REGIONS OF DH-4;

Depth (Feet)

Group or

pattern

Abundances :

(Percent)

$\mathrm{SiO}_{2}$
$\mathrm{Al}_{2} \mathrm{~S}_{3}$
$\mathrm{FeO}$
$\mathrm{MgO}$
$\mathrm{CaO}$
$\mathrm{Na}_{2} \mathrm{O}$
$\mathrm{K}_{2} \mathrm{O}^{-}$
$\mathrm{TiO}_{2}$

In Parts per i.ti. 11 ion

$\mathrm{Sc}$
$\mathrm{Eu}$
$\mathrm{Ba}$
$\mathrm{Cr}$

Sample Number
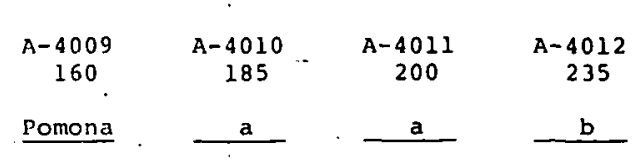

51

13.3

$$
52
$$

13.6

10.8

$$
10.8
$$

50

14.1

11.1

6.1

7.4

10.2

2.4

0.3

1.7

5.8

9.0

2.4

0.9

18

9.0

2.3

0.9

1. 6

49
15.6
9.8
9.2
10.3
2.2
0.1
1.3

27

33
1.6
42
500
92

27
1.8

26

1.8

$38^{\circ}$

830

111
30

1.1

42

490

295
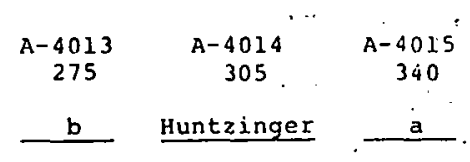

A-4016

365

Wahluke

50

15.7

51

51

53

10.1

15.1

13.9

13.6

9.0

10.7

11.5

12.2

7.6

6.0

5.3

10.6

9.7

8. 8

8.1

2.2

2.4

2.4

2.8

0.3

0.8

1.4

1.9

1.4

1.7

1.7

1.8

Samples $A-4009, A-4010$, and $A-4015$.

\begin{tabular}{|c|c|c|c|}
\hline 28 & 26 & 26 & 25 \\
\hline 1.0 & 1.4 & 2.0 & $\therefore 2.0$ \\
\hline 45 & 39 & 37 & 37 \\
\hline 390 & $560^{\circ}$ & 830 & 1,160 \\
\hline 269 & 173 & $97^{\circ}$ & $\therefore \quad \therefore 31$ \\
\hline
\end{tabular}

${ }^{b}$ Samples $A-4012$ and $A-4013$. 


\section{DH- 5 COMPARISONS}

The DH-5 correlations are shown in Figures $A-9$ and $A-10$ in Appendix A. The data used for $S C$ and Co in Samples A-5021, A-5022, A-5024, and A-5026 were taken from Tatman, ${ }^{(2)}$ as there were apparently typographical errors in the Sc values and one Co value given in ARH-ST-137.(1) The Elephant Mountain group was revised in the same manner as described for $D D H-1$ and part of its correlations is also shown in Figure A-9 in Appendix A. The top flow correlates well with this revised Elephant Mountain group. There are smaller correlations with the ward Gap and Priest Rapids I, II, and III. 'I'he' Priest Rapids' correlation would likely be greatly reduced if no trace elements were rejected, as the $\mathrm{Sc}$ abundance of these tlow groups is quite different from that of Elephant Mountain. More extensive measurements of trace elements on the core samples and reference groups might distinguish much more completely between the ward Gap and Elephant Mountain groups. Stratigraphic position, plus the paleomagnetic normal polarity of the Elephant Mountain and reversed polarity of the Priest Rapids, provides a simple means for distinguishing the Elephant Mountain and Priest Rapids. Good correlations occur for rocks between the Pomona group and rocks from depths of 340 to 460 feet in DH-5. A small correlation of 3 of these rocks with the Huntzinger would be greatly reduced if their trace elements had also been measured. The next group of rocks correlates well with the Huntzinger group. There is no evidence of the Wahluke or Umatilla group in $\mathrm{DH}-5$. Two rocks from a depth of $\sim 700$ feet correlate well with the Priest Rapids IV flow. From depths of 740 to 1,680 feet, there are correlations with Priest Rapids I, II, and III, Roza, Sentinel Gap, Sand Hollow, and Ginkgo groups, but unambiguous assignments cannot be made from the existing chemical evidence alone. Better and more extensive trace element measurements might make conclusive distinctions between these groups possible. From 1,840 to 2,550 feet, nearly all rock groups correlate to some degree with the Museum and Rocky Coulee 
groups. These rocks also correlate well with a group (not shown in the figures) of rocks from selah Butte as discussed for DH- 4 samples.

In $\mathrm{DH}-5$, there were 14 minor correlations with those groups shown in Figure A-9 in Appendix A for 120 rocks from below $2,19,0$ feet. There were 2 correlations with the wahluke group, 7 with the Gable Mountain group, and 5 with the Umatilla group. For those groups shown in Figure A-10 in Appendix A, there were 2 minor correlations below 2,790 feet. Inclusions of trace element data would very likely have eliminated all of these. Although DH-5 was drilled to a total depth of 5,002 feet (Vnlume II, Page C-151, ARH-ST-137) (1) the plots on Figure A-10 in Appendix A do not extend below 2,800 feet because of the lack of designated type localities for the deeper lower Yakima flows. 
APPENDIX A

FIGURES $A-1-A-10$ 


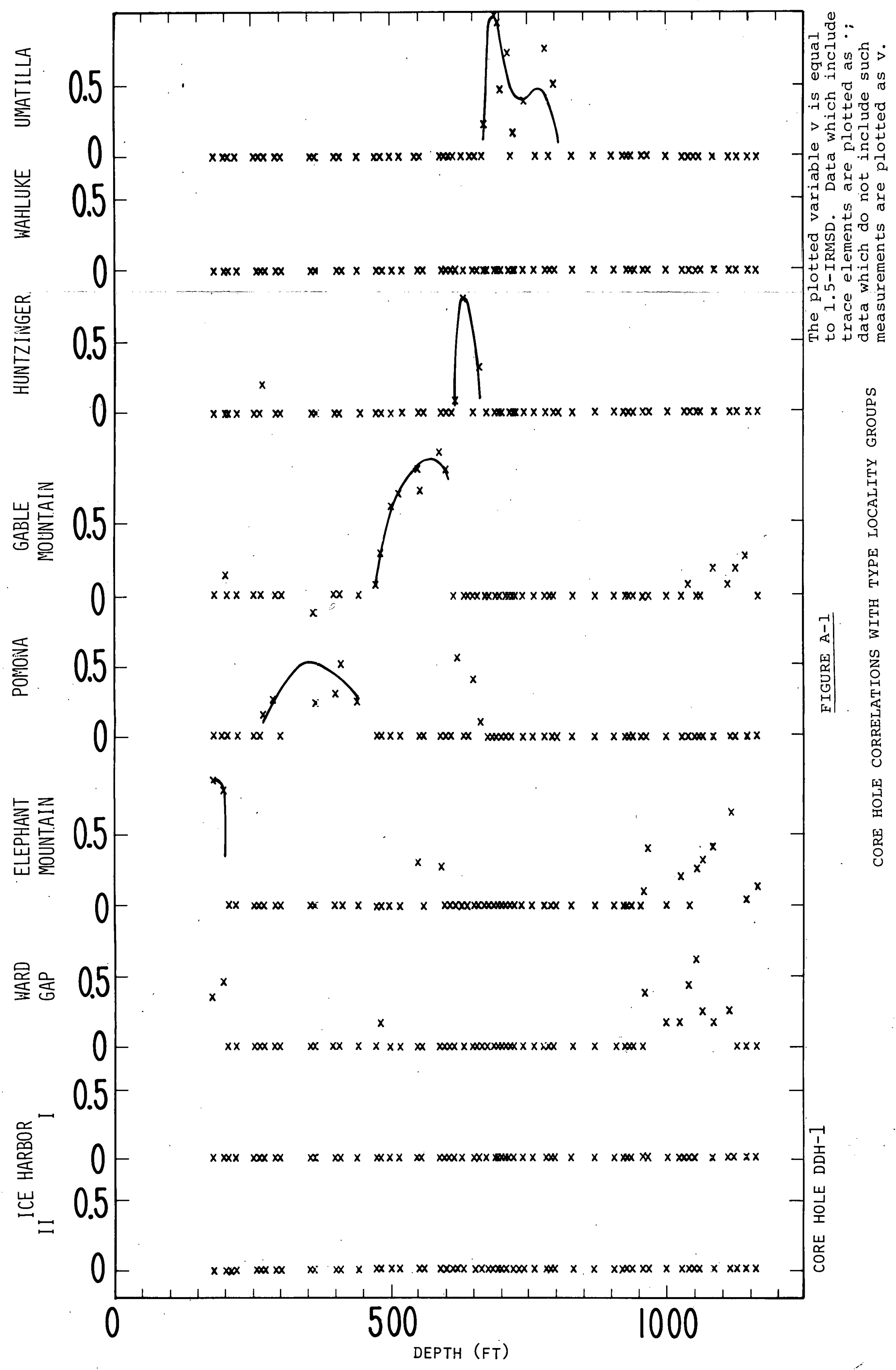




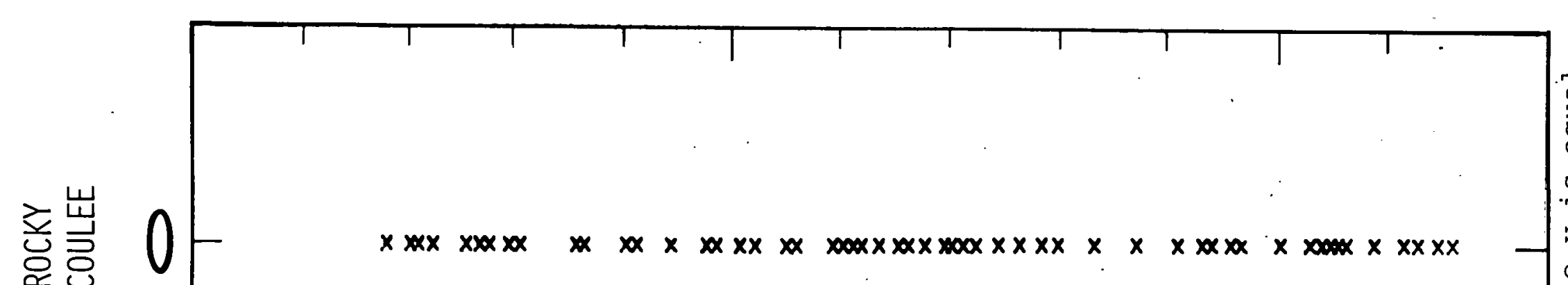

: :

绕

a.

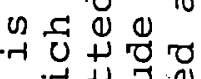

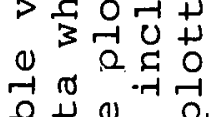

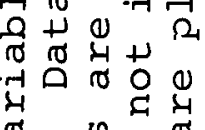

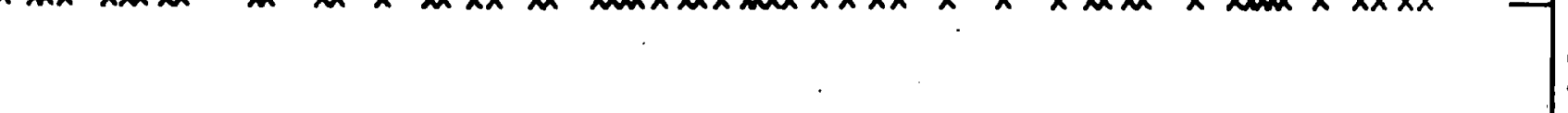

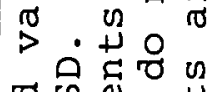

0.5

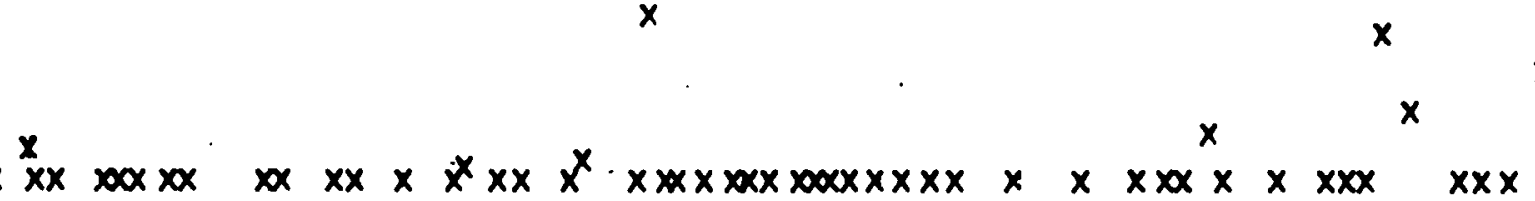

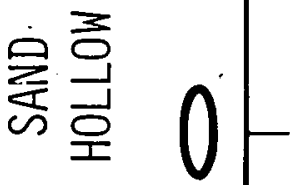

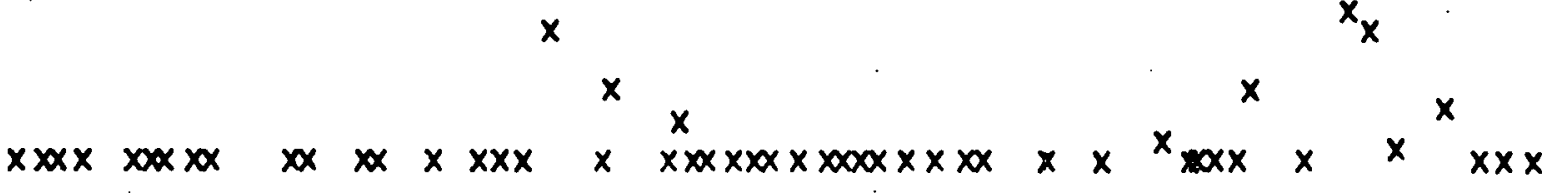

$0.5-$

岕岕 0

$x_{x}^{x} x^{x} x^{x} x$

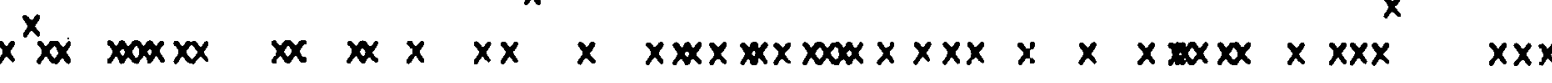

$0.5-$

文 0

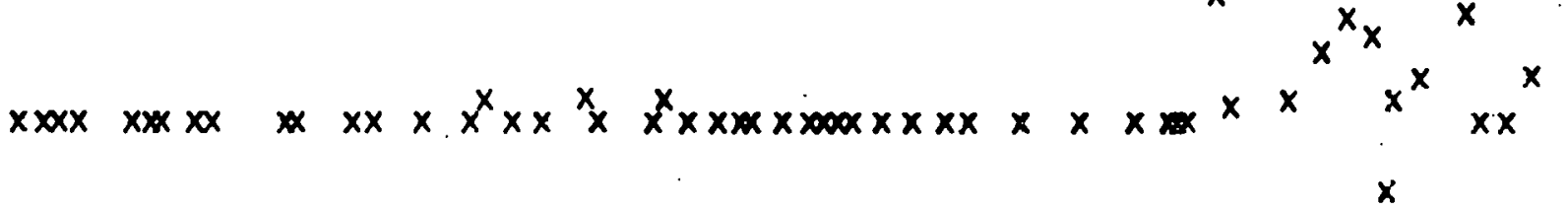

0.5

$x$

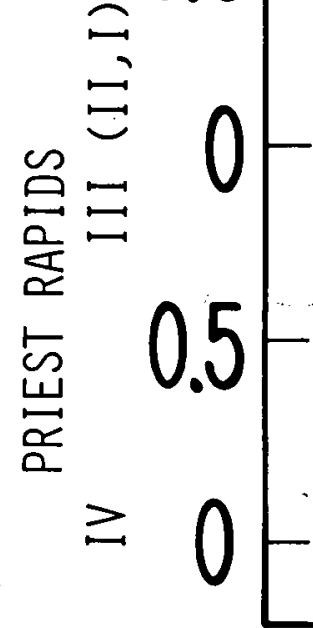

$x$

$x=\sin x \sin x$

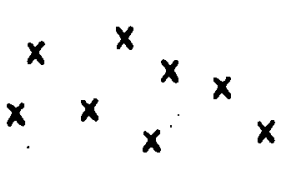

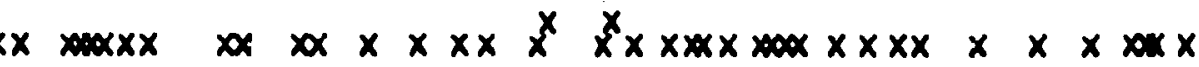




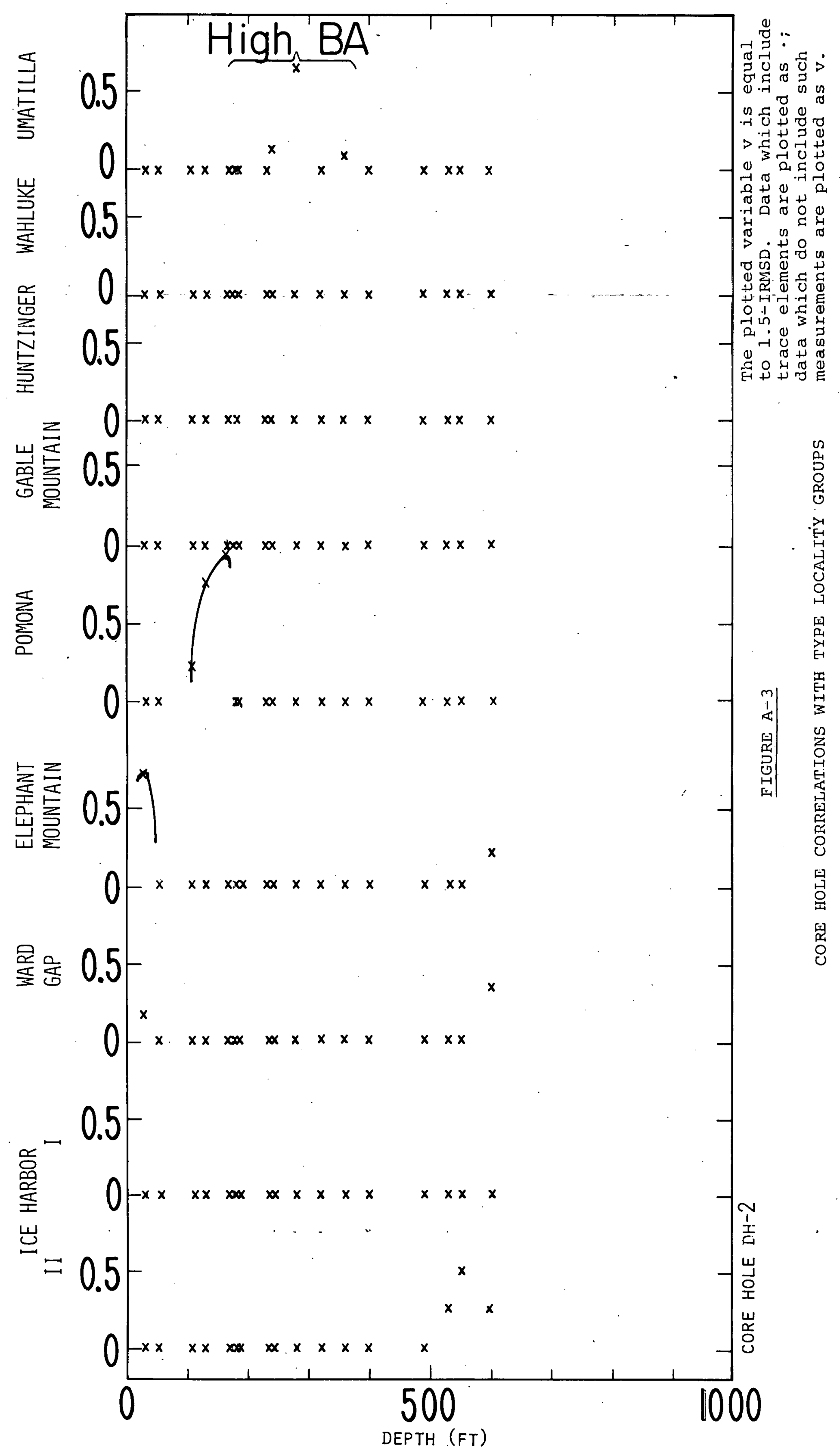


$m$
1
1
0
1
1
3
0
1
1
0
0
0

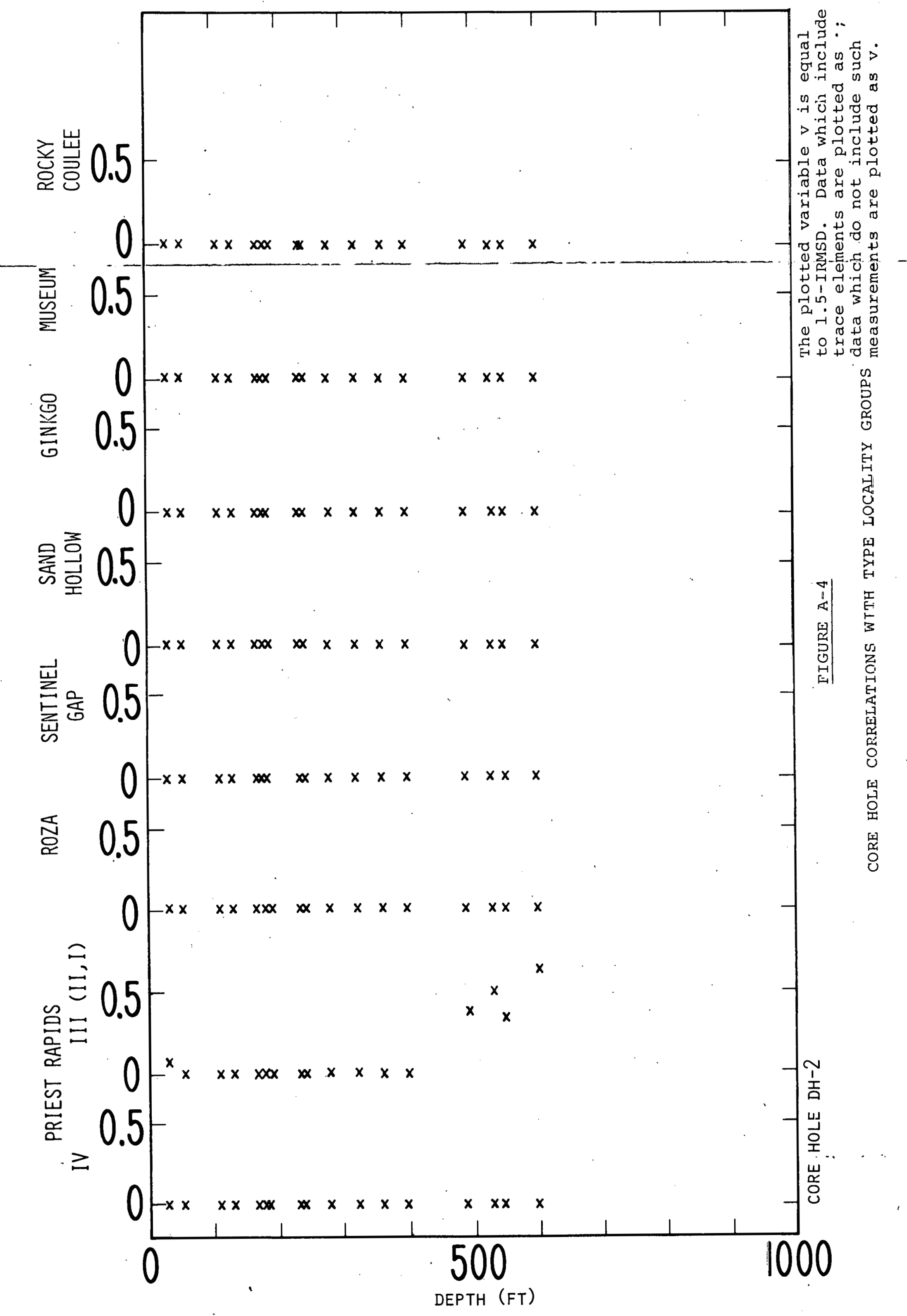

$X B L 776-1076$ 


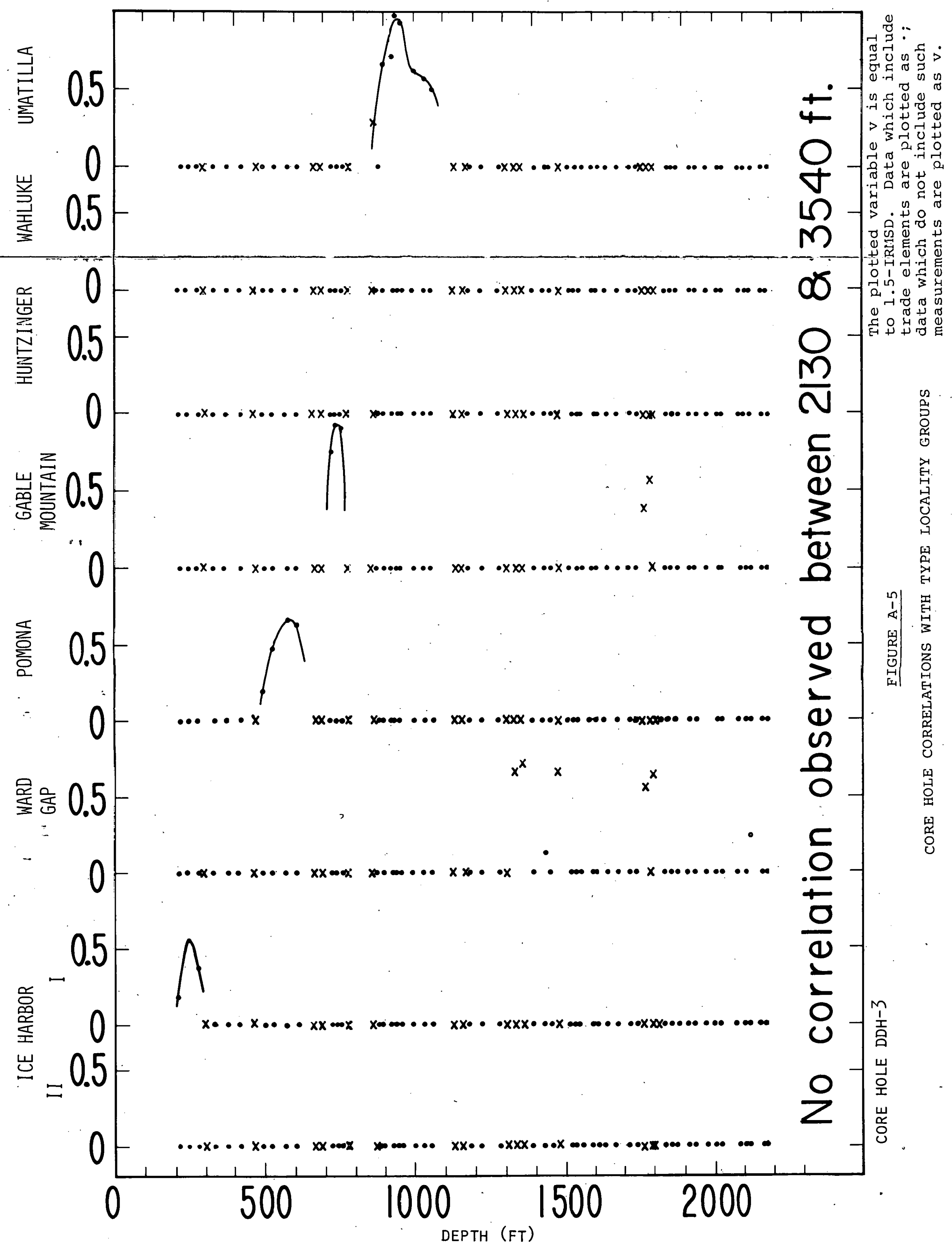

$X B L 776-1080$ 


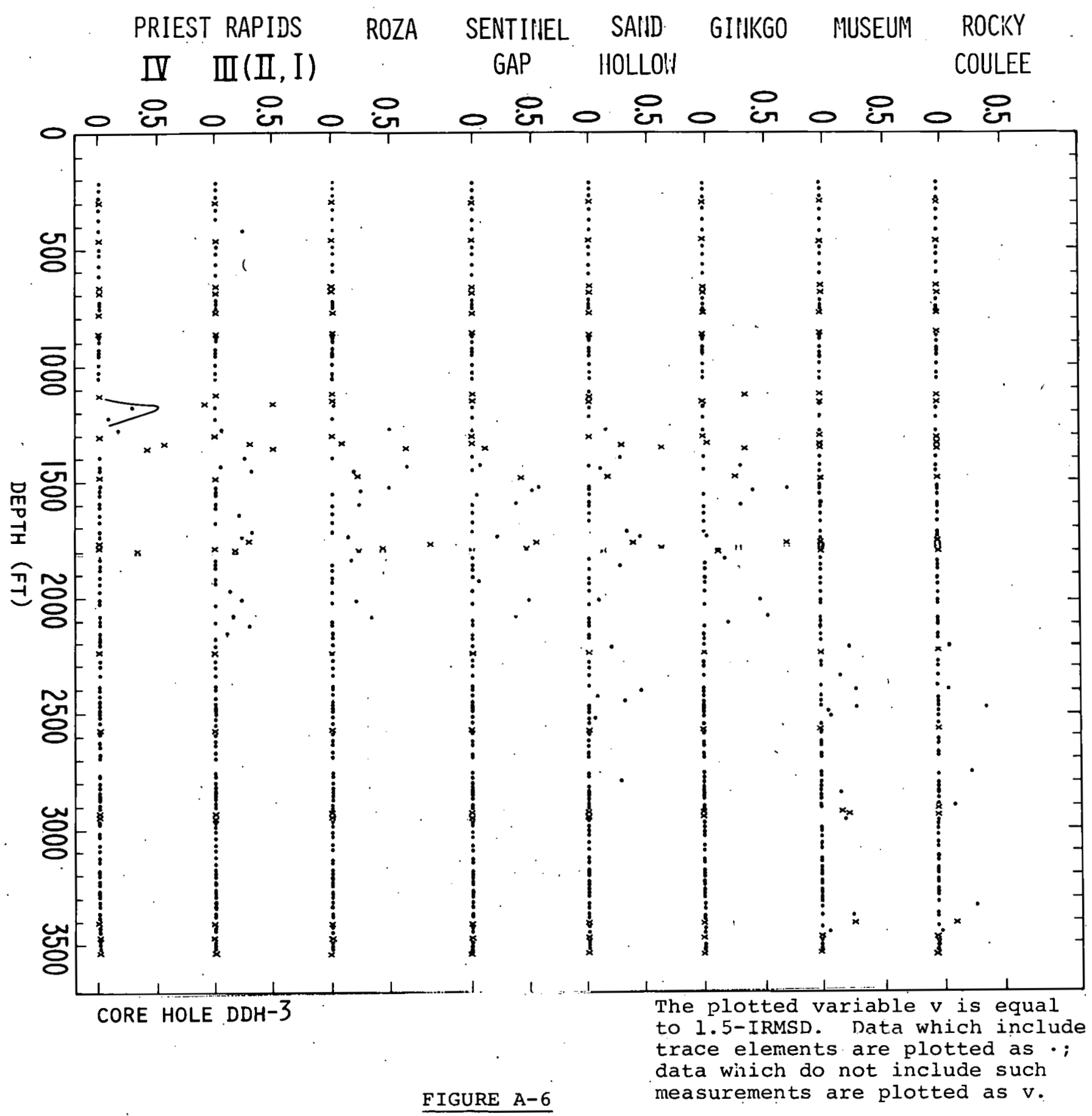

CORE HOLE CORRELATIONS WITH TYPE LOCALITY GROUPS 


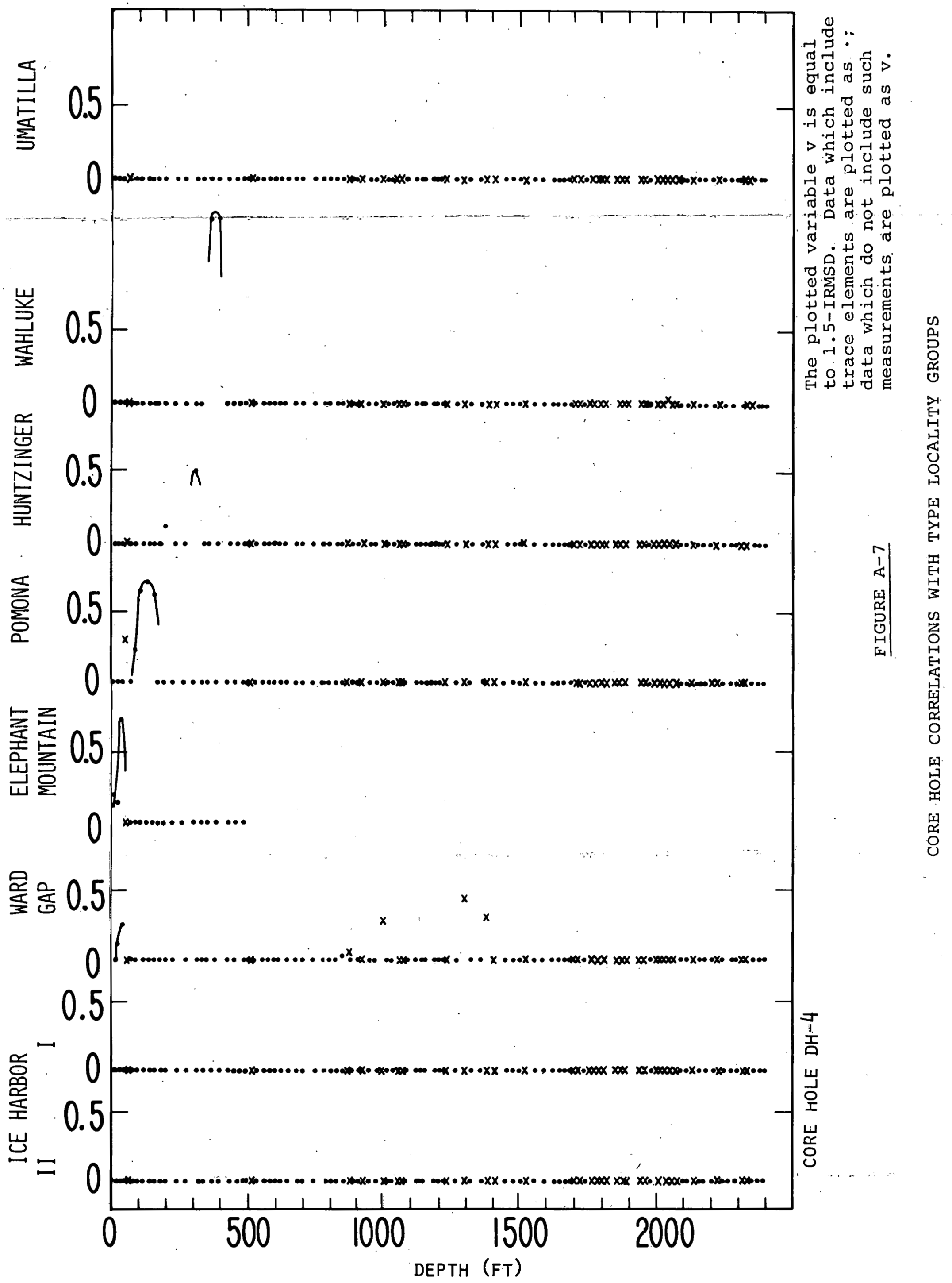

XBL776-1077 
$m$
1
-1
0
1
1
3
0
1
1
0
0
0

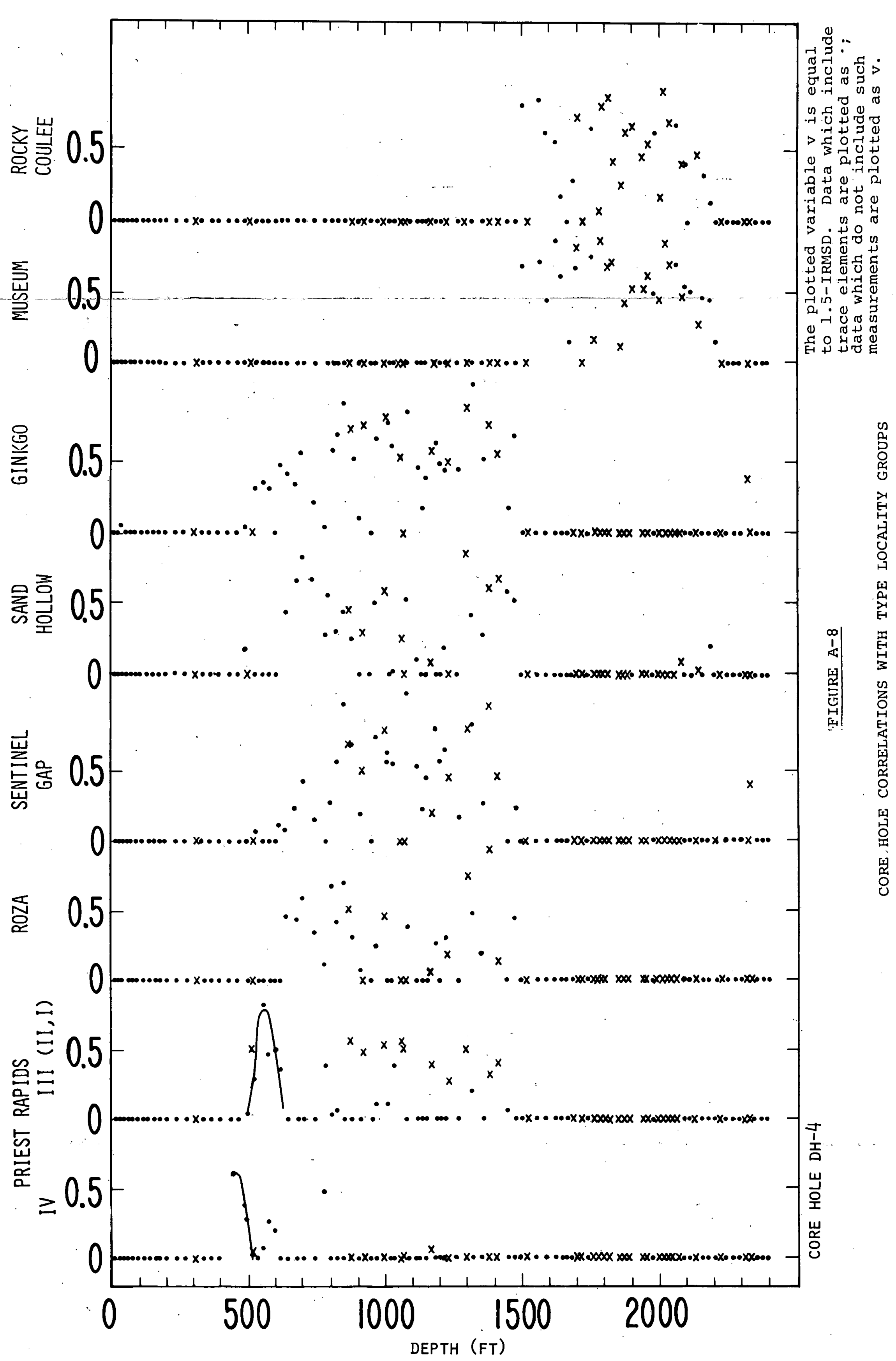

XBL776-1072 
$m$
1
-1
1
1
-1
3
0
1
0
0
0

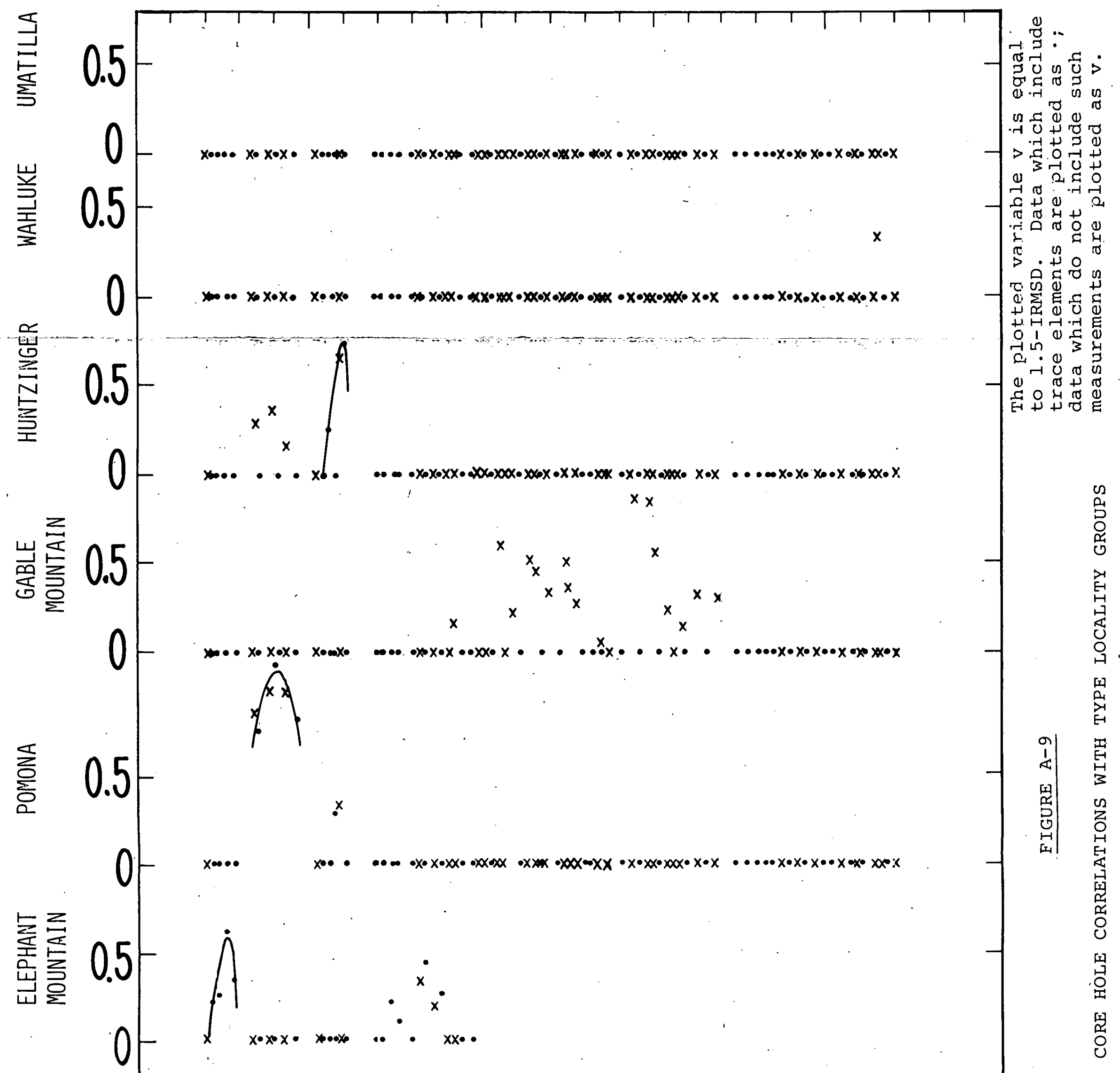

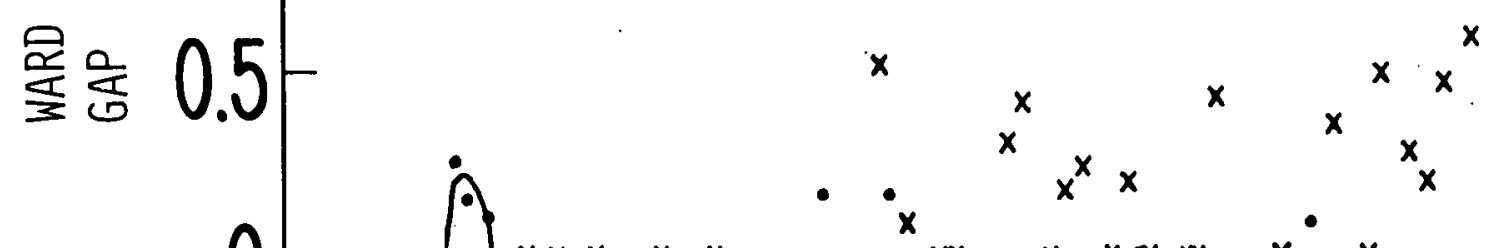

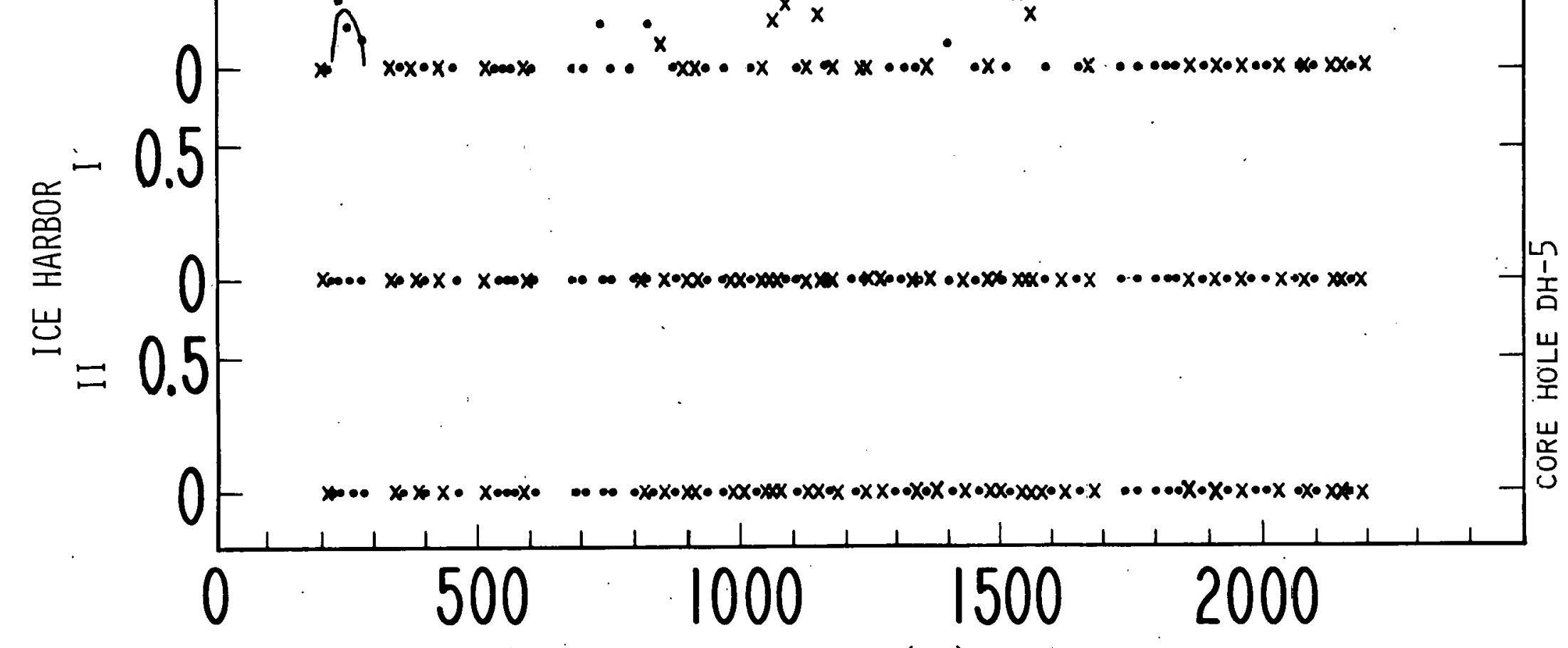

DEPTH（FT） 


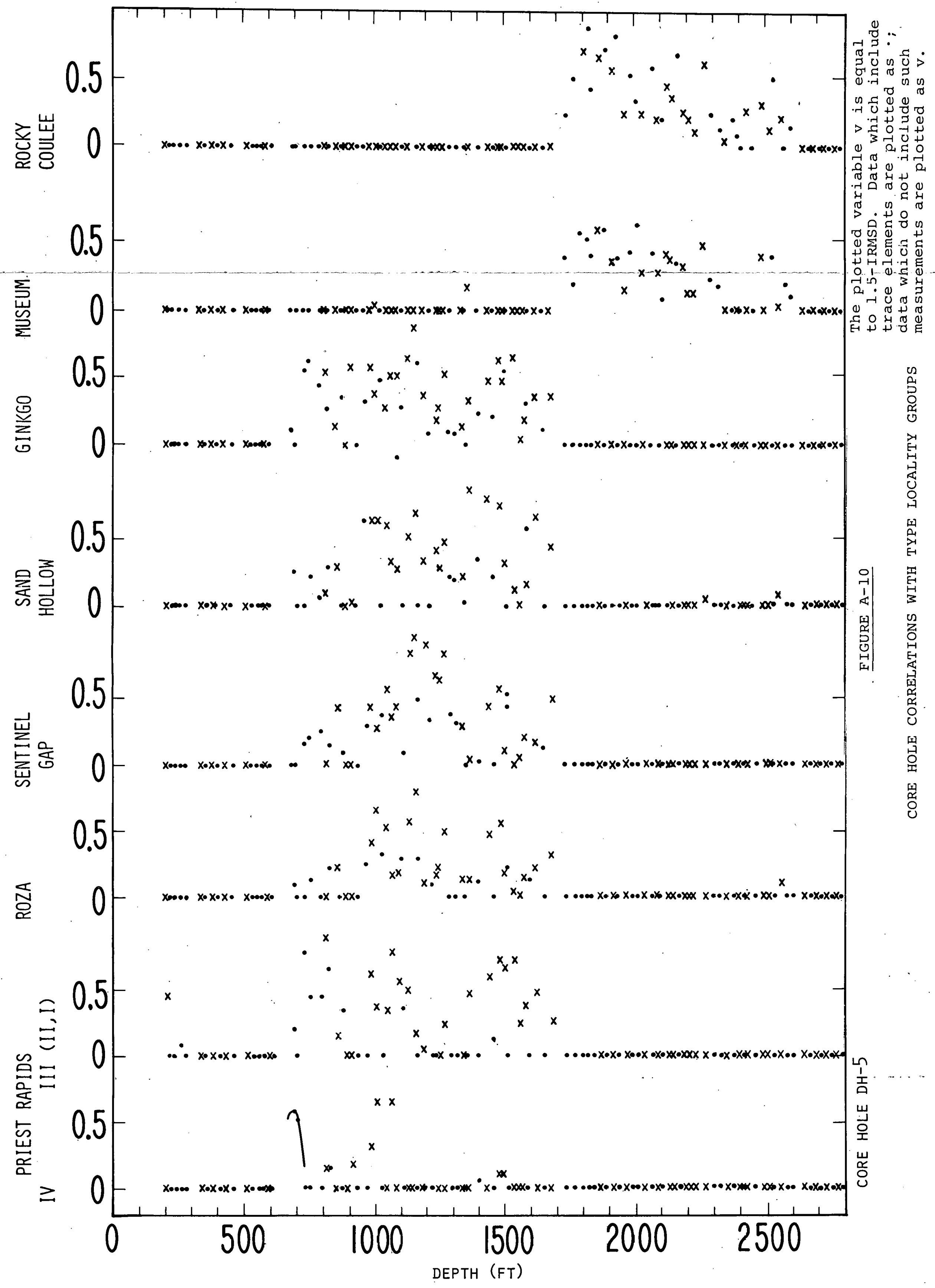




\section{ACKNOWLEDGMENTS}

We are greatly indebted to Mr. R. E. Isaacson cand: Dr. R. A. Deju of Rockwell Hanford Operations for many helpful discussions. Dr. J. Apps and Mr. H. Bowman of the Liawrence Berkeley Laboratory also gave freely of their time and insight during the course of this project. We are very appreciative. of the constructive comments and overview of the project by Professor I. Perlman of the Hebrew University of Jerusalem. The programming done by Mr. D. Gok at Lawrence Berkeley Laboratory and the rapid turn-around provided by the Lawrence Berkeley Laboratory central computer facilities were most helpful. A significant portion of the funding for this project was provided by the waste Isolation Program of Rockwell Hanford operations. 


\section{REFERENCES}

1. Staff, Research and Engineering Division, Preliminary Feasibility Study on storage of Radioactive Wastes in Columbia River Basalts, ARH-ST-137, Atlantic Richifield Hanford Company, Richland, Washington (November 1976).

2. J. B. Tatman, Geochemical Variation of Columbia River Basalts Beneath the Hanford Reservation, Washington, ARH-2610, Atlantic Richfield Hanford Company, Richland, washington (September 1972).

3. M. R. Brock and M. J. Grolier, Chemlcal Analyses of Jos Dajalt Eamplos from tho Columhia River Plateau. Washington, oregon, and Idaho, U. S. Geologledl Sulvey open File Report (1973).

4. T. L. Wright, M. J. Grolier, and D. A. Swanson, "Chemical Variation Related to the Stratigraphy of the Columbia River Basalt," Geological Society of America Bulletin, $84,371-386(19 \overline{73})$.

5. H. R. Bowman, H. U. Schmincke, and A. Herbert, "The Homogeneity of Columbia River Basalt and Its Relation to a Coastal Basalt Flow," Lawrence Berkeley Laboratory Nuclear Chemistry Division Annual Report - 1973, LBL-2366, Lawrence Berkeley Laboratory, Berkeley, California, (May 1974).

6. Handbook of Chemistry and Physics, 47 th Edition, A-152, Chemical Rubber Company, Cleveland, Ohio (1966).

7. A. W. Ward, Jr., Petrology and Chemistry of the Huntzinger Flow, Columbia River Basalt, Washington, ARH-SA-272, Atlantic Richfield Hanford Company, Richland, Washington (November 1976). 


\section{DISTRIBUTION}

Number of

Copies

1.

6

1

25

1
$1 \quad$ Eastern Washington University

\section{Battelle Columbus Laboratories}

J. Batch

Battelle-Northwest

T. W. Ambrose (2)

J. R. Eliason

A. M. Platt (2)

R. W. Wallace

Central Washington University

Department of Geology

Consultants and Subcontractors

J. F. T. Agapito

Boeing Computer. Services Richland, Inc.

Colorado School of Mines

ENSCO, Inc.

Fenix \& Scisson, Inc. (2)

Geoscience Research Consultants

Idaho Bureau of Mines and Geology

Lawrence Berkeley Laboratory

Oregon State Department of Geology and

Mineral Industries

F. L. Parker

The Pennsylvania State University

I. Remson :

Seismograph Services

W. K. Summers and Associates

U. S. Bureau of Mines-Spokane

U. S. Geological Survey-Water Resources

U. S. Geological Survey-Western Division

University of Minnesota

University of Oregon

Washington State Department of Ecology

Washington State Department of Natural Resources

Washington State University

A. C. Waters

Western Washington University

Department of Geology

The Geological Societ.y of America, Inc.

J. C. Frye 
Number of Copies

1

7

1

5

1

1

1

2
Kansas State Geological Survey

W. W. Hambleton

Lawrence Berkeley Laboratory
J. Apps
F. Asaro (3)
H. Bowman
D. Gok
H. V. Michel

Lawrence Livermore Laboratories

L. Ramspott

Sandia Laboratories

O. E. Jones

R. W. Lynch

W. D. Weart

Union Carbide Corporation, Nurlear Division Office of waste Isolation

A. L. Boçh

T. F. Lomenick

W. C. Mcclaill

A. S. Quist

C. D. Zerby

United Nuclear Industries, Inc.

R. K. Robinson

U. S. Army Corps of Engineers

walla walla vistriel Geuluyist

U. S. Bureau of Reclamation

Columbia Basin Project Geologist

U. S. Department of Energy-Albuquerque Operations Office

D. Davis

D: T. Schueler 
Number of

Copies

13

1

1

14
U. S. Department of Energy-Headquarters
C. R. Cooley
C. A. Heath
J. M. Deutch
C. Klingsberg
K. P. Donovan
R. N. Ng
W. K. Eister
R. Stein
M. W. Frei
D. L. Vieth
C. H. George
J: B. Work
J. L. Gilbert

U. S. Department of Energy-Nevada Operations Office

D. G. Jackson

U. S. Department of Energy-Oak Ridge Operations office

J. J. Schreiber

U. S. Department of Energy-Richland Operations Office
J. N. Anttonen
T. A. Bauman
J. C. Cummings
O. J. Elgert
R. B. Goranson
P. G. Harris

A. G. Lássila

D. J. Squires (4)

F. R. Standerfer

M. W. Tiernan

P. S. Van Loan

U. S. Department of Energy-Technical Information Center

U. S. Environmental Protection Agency

$$
\begin{array}{ll}
\text { R. } & \text { Kaufman } \\
\text { G. L. } & \text { Meyers } \\
\text { J. } & \text { Sceva }
\end{array}
$$

U. S. Geological Survey

G. D. DeBuchanne

P. R. Stevens

W. S. Twenhofel

U. S. Nuclear Regulatory Commission
W. P. Bishop
J. C. Malaro
E. P. Regnier 


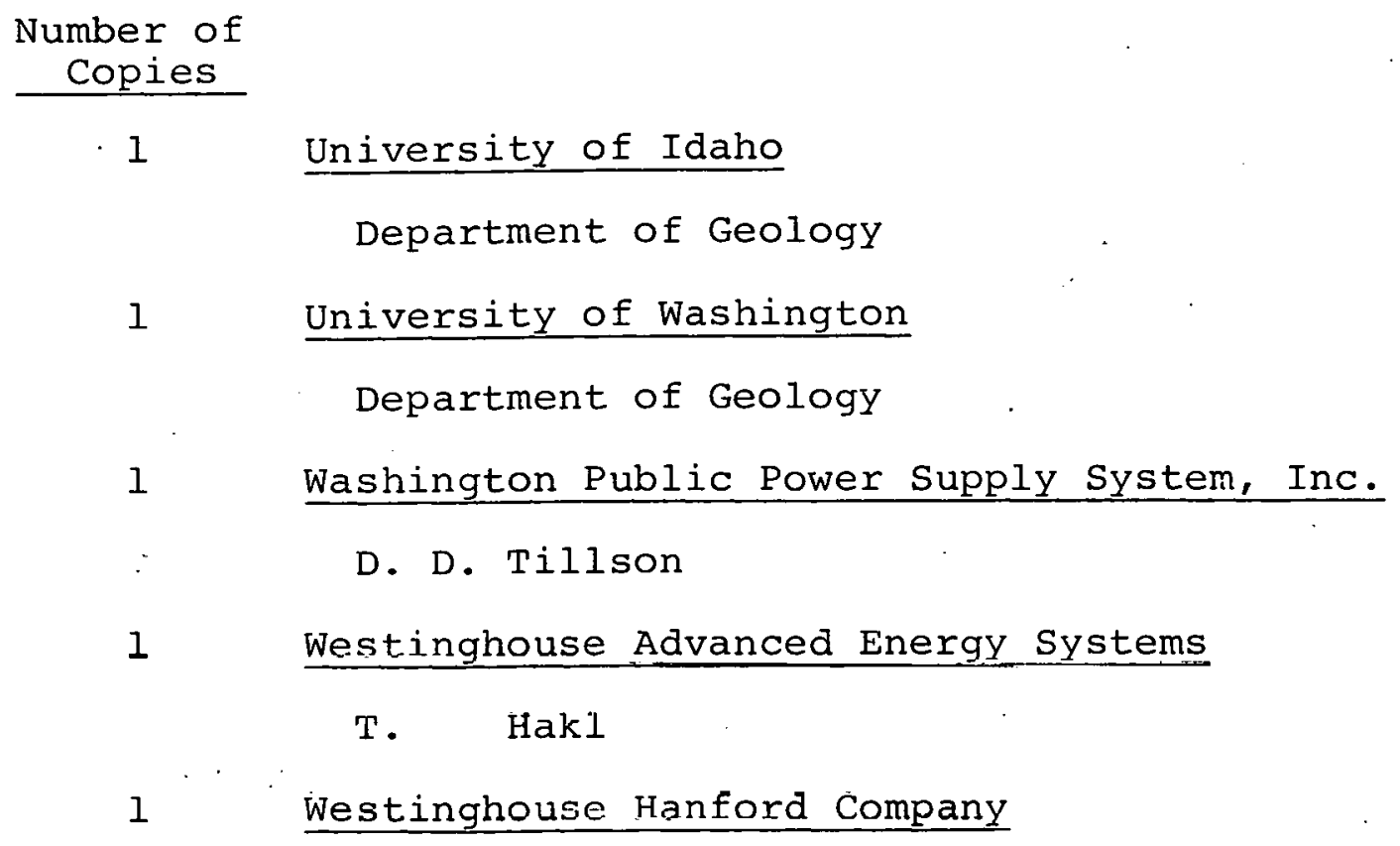

A. G. Blasewitz

89 Rockwell Hanford Operations

H. Babad

D. J. Cockeram

R. A. Deju

P. J. Fritch

R. J. Gimera

R. D. Hammond

W. F. Heine

J. E. Kinzer

E. J. Kosiancic

J. II. Roeekcr

D. A. Turner

D. D. Wodrich

Waste Isolation Program Library (75)

Document Services (2) 


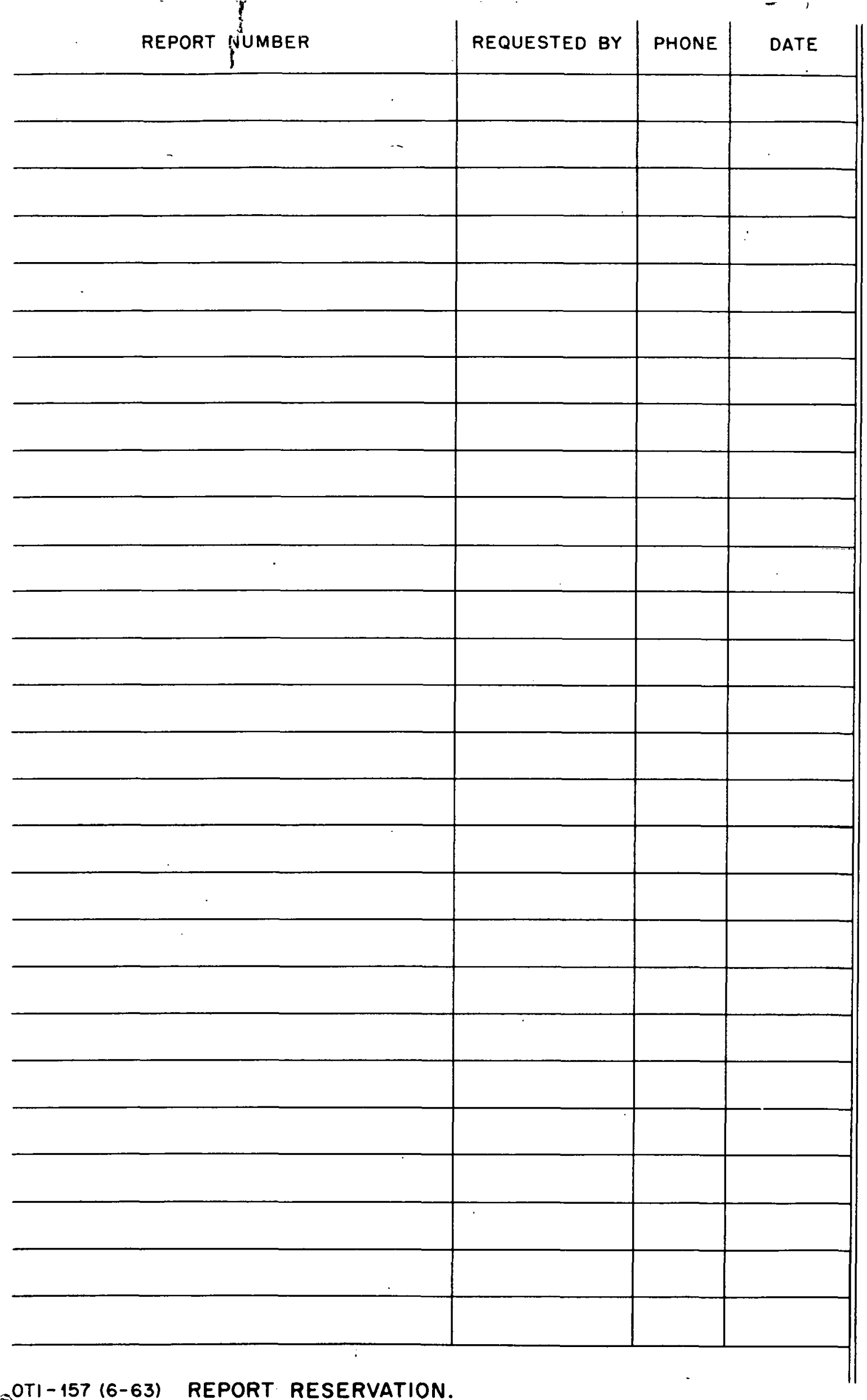

Instructions:

1. To reserve a master folder, fill in the columns above and file this form at the filing point for the master folder.

Remorks: 